\title{
La compatibilidad de la normativa catalana de seguridad industrial con la Directiva europea de servicios y su transposición legislativa en España
}

\author{
Carlos Padrós Reig \\ Profesor Titular de Derecho Administrativo. Universidad Autónoma de Barcelona \\ Magistrado de lo contencioso-administrativo. Barcelona \\ carlos.padros@cerhum.es
} La Directiva europea de servicios en el mercado interior establece la libertad de entrada para las actividades económicas. Esta normativa ha sido objeto de transposición en España mediante las Leyes 17/2009 y 25/2009. No se prevé un régimen especial para la garantía de la seguridad industrial. Los organismos de control, pueden quedar sujetos a autorización administrativa bajo estrictas condiciones de igualdad y proporcionalidad. La Comunidad Autónoma de Cataluña ha mantenido su normativa (anterior y posterior) en clara contradicción con las normas del Estado y con los principios de derecho europeo. inspección de vehículos.

\section{The compatibility of Catalan regulation on industrial safety with the Internal Market Services Directive and its legislative implementation in Spain}

\begin{abstract}
The Internal Market Services Directive establishes the freedom of entry for economic activities. This European norm has been object of implementation in Spain with the passing of Act 17/2009 and Act 25/2009. There is no special scheme foreseen for the guarantee of industrial safety. Industrial safety control entities, may be subjected to administrative authorisation under strict conditions of equality and proportionality. The Autonomous Community of Catalonia has maintained its regulations (previous and new ones) in clear inconsistency with State Law standards and with principles of European Law.
\end{abstract}

Key words

Services Directive; industrial safety; implementation into national legal order; entities for control; vehicle inspections. 


\section{PRESENTACIÓN}

La llamada Directiva Bolkenstein, Directiva europea de servicios en el mercado interior (en adelante DSMI o la Directiva), ha provocado -antes y después de su aprobación- un considerable revuelo legal y mediático. Antes de su aprobación, se vio la normativa como un ataque frontal a las condiciones laborales y sociales de los trabajadores en los países con mayores niveles de protección social. La imagen del fontanero polaco que explotaron los contrarios a la Constitución Europea en Francia era bien significativa. Efectivamente, sobre la base de una aplicación automática del principio de reconocimiento mutuo y de legislación del país de origen, una empresa polaca de servicios podría efectuar trabajos en España aplicando la normativa salarial y social de Polonia. Ello, llegado el caso, hubiera puesto en serias dificultades a los trabajadores españoles o franceses.

Lo cierto es que, ni la Directiva establecía exactamente un principio tan automático ni la intervención del Parlamento europeo en la elaboración de la norma permitió esa lectura. Todos los elementos que podían presagiar una especie de dumping social dentro de Europa (ahora con 27 Estados con niveles de desarrollo y prestaciones sociales muy dispares), fueron eliminados. La Directiva, pues, no se aplica a las condiciones laborales o sociales de los trabajadores.

Sin embargo, la Directiva persigue un fin fundamental como es la facilitación de la libre prestación de servicios en el mercado interior. A lo largo de los años hemos podido observar un espectacular crecimiento y consolidación del comercio comunitario relativo a mercancías. Ello no ha ido acompañado en igual medida en el caso de los servicios ( $y$ aunque en menor medida, tampoco, en el caso de los capitales o inversiones intracomunitarias). La llamada Estrategia de Lisboa para impulsar la creación de empleo de calidad y la mejora de la competitividad y el Informe sobre el estado de subdesarrollo del comercio de servicios en Europa impulsaron la redacción de la DSMI.

Eliminados sus aspectos más problemáticos, la Directiva sigue suponiendo una transformación importante del papel de la Administración pública como reguladora del acceso a la prestación de los servicios. En otras palabras, si hasta ahora la prestación de muchos servicios económicos debía contar con la autorización de la Administración (control ex ante), a partir de ahora, se establece el principio de libertad de prestación con una simple comunicación y la Administración deberá poder controlar a posteriori si se cumplen las condiciones autodeclaradas por el sujeto privado. Se trata en definitiva de simplificar administrativamente las condiciones de ejercicio de una actividad de naturaleza económica (servicio). Para ello, la Directiva contiene importantes disposiciones sobre simplificación administrativa, fomento de la calidad de los servicios y cooperación interadministrativa entre Estados (ventanillas únicas y como se ha hecho ya en Alemania, la existencia de oficinas de información y asesoramiento a los empresarios extranjeros que quieran desarrollar actividades en su país

184 (Einheitlicher Ansprechpartner Deutschland)). 
A nadie se le escapa la fenomenal trascendencia del nuevo paradigma que afecta, de manera muy directa y contundente a la Administración pública. A juicio de Fernández Rodríguez (Fernández Rodríguez, 2007: 194), “la Directiva 2006/123 no es novedosa en lo que a su contenido respecta. No ha tenido necesidad de serlo, porque el trabajo ya estaba hecho por el Tribunal Europeo, cuya jurisprudencia se limita a recoger. La única novedad, si puede decirse así, una novedad ciertamente formidable por su alcance, radica, justamente, en esto, es decir, en haber convertido esa jurisprudencia en una disposición general y en haber montado un sistema específico para asegurar el efectivo cumplimiento de ésta en todo el ámbito de la Unión. El contenido de la Directiva es, pues, tan simple como claro. Parte, como procede siempre que una libertad está en juego, del principio de proporcionalidad, a partir del cual afirma su artículo 9 que "Los Estados miembros solo podrán supeditar el acceso a una actividad de servicios y su ejercicio a un régimen de autorización cuando dicho régimen, amén de no ser discriminatorio para el prestador, resulte indispensable por una razón imperiosa de interés general y no pueda conseguir mediante una medida menos restrictiva, en concreto - dice el precepto- porque un control a posteriori se produciría demasiado tarde para ser realmente eficaz. Si estas condiciones se cumplen, será legítimo establecer un control preventivo de signo autorizatorio, pero el otorgamiento o denegación de la autorización deberán basarse en criterios que delimiten el ejercicio de la facultad de apreciación de las autoridades competentes con el fin de que dicha facultad no se ejerza de forma arbitraria"”.

Sin embargo, también se ha destacado que "la transposición de la DS conllevará un importante esfuerzo de adaptación de la legislación sectorial y una reconsideración significativa sobre la actividad de intervención de la Administración Pública en las actividades privadas y en concreto en las de servicios"2.

Más crítico se muestra, sin embargo, el profesor Parejo Alfonso (2009: 34) para quien no estamos ante una norma de desregulación sino de liberalización, que parte de un concepto de "obstáculo ilegítimo a la libre competencia en el mercado" tan amplio, que pone bajo sospecha de restricción indebida cualquier regulación jurídicopública del acceso al mercado de las actividades de servicios o de ejercicio de éstas, es decir, lo que en principio no es otra cosa que ordenación del uno y el otro para su inserción armónica en el sistema de convivencia colectiva en función de los restantes bienes y valores en presencia"3.

$1 \quad$ Fernández Rodríguez, T.R. (2007): “Un nuevo Derecho Administrativo para el mercado interior europeo" Revista Española de Derecho Europeo, n. ${ }^{\circ} 22$, p. 194

2 Gutiérrez Colomina, V. "La incidencia de la Directiva de servicios 2006/123/CE en el Urbanismo" documento disponible en http://www.inap.map.es/NR/rdonlyres/BDF38206-06E4-435B-9E08-541A3B9C5DBD/0/8.pdf. (Acceso 29 de abril de 2010).

3 Parejo Alfonso, L. (2009a): “La desregulación de los servicios con motivo de la Directiva BoIkenstein. La interiorización con paraguas y en ómnibus de su impacto en nuestro sistema” El Cronista del Estado Social y Democrático de Derecho n. ${ }^{\circ}$ 6. Del mismo autor, de manera más ampliada, Parejo Alfonso, L. (2009b): "La Directiva Bolkenstein y la Ley paraguas: ¿Legitima el fin cualesquiera medios para la reconversión del Estado “autoritativo"? Revista Española de Derecho Europeo, n. 32. 
En definitiva, la doctrina ha analizado con profusión esta importante normati$\mathrm{va}^{4}$. Con este breve trabajo, nos proponemos presentar sumariamente los principales contenidos de la Directiva Europea (apartado II); presentar la actividad de transposición normativa en España de las previsiones de la Directiva que ha tenido lugar mediante la aprobación de dos leyes: la Ley 17/2009, de 23 de noviembre (llamada Ley paraguas), así como la Ley 25/2009 de 22 de diciembre (Ley Ómnibus) (apartados III y IV); para finalmente ver la compatibilidad de todo ello con la normativa catalana de seguridad industrial (Ley del Parlamento de Cataluña 12/2008, de 31 de julio, de Seguridad Industrial y su desarrollo reglamentario mediante el Decreto 30/2010 de 2 de marzo y otras normas conexas (apartado V). Con ello estaremos en disposición de analizar qué sucede en casos donde la actividad autonómica de transposición de Directivas antecede a la propia del Estado y qué supone para un ordenamiento jurídico complejo como el español la disonancia entre normas estatales y normas autonómicas en la adopción del modelo de transposición de la DSMI.

Siguiendo consolidada jurisprudencia constitucional al respecto, la transposición al Derecho interno de las obligaciones de la normativa europea corresponde al nivel administrativo y legislativo interno de cada país (principio de autonomía institucional y procedimental) ${ }^{5}$. Sin embargo, esta diversidad autonómica en la transposición puede necesitar en algunos casos de normativa estatal unificadora. Como sucede en el presente caso, la normativa catalana podría ser compatible con la Directiva (pues ésta admite distintos modelos normativos) pero disconforme con la legislación básica del Estado dictada posteriormente también en transposición de la DSMI. Además, se une a ello el problema de las diferentes entradas en vigor de las normativas. La Directiva es obligatoria para los Estados miembros (lo que incluye las Administracio-

4 Además de los trabajos ya citados y sin ninguna pretensión de exhaustividad, vide igualmente, Muñoz Machado, S. (2009): “Ilusiones y conflictos derivados de la Directiva de Servicios” Revista General de Derecho Administrativo n. 21; De la Quadra Salcedo, T. (Dir.) (2009): El mercado interior de servicios en la Unión Europea. Estudios sobre la Directiva 123/2006/CE relativa a los servicios en el mercado interior. Marcial Pons, Madrid; González García, J.V. (2009): “La transposición de la Directiva de servicios: aspectos normativos y organizativos en el Derecho español" Revista Española de Derecho Europeo n, 32; Linde Paniagua, E. (2008): “Notas sobre el objeto, ámbito y reglas de aplicación de la Directiva relativa a los servicios en el mercado interior” Revista de Derecho de la Unión Europea n. 14; también Rivero Ortega, R. (2009): "Antecedentes, principios generales y repercusiones administrativas de la Directiva de Servicios: problemas de su transposición en España” Revista de Estudios Locales, n. ${ }^{\circ} 122$.

5 Albertí Rovira, E. (2006): “El desarrollo y ejecución por las Comunidades Autónomas de la normativa comunitaria en materias de competencia compartida con el Estado" en la obra colectiva Estatuto y Unión Europea. Institut d’Estudis Autonòmics. Barcelona; Cabellos Espiérrez, M.A. (2001): Distribución de competencias, derechos de los ciudadanos e incidencia del derecho comunitario. Centro de Estudios Políticos y Constitucionales, Madrid; Ruiz Ruiz, F. (1995): "Las competencias de las CCAA en el desarrollo normativo y la ejecución del derecho comunitario europeo”, Revista Española de Derecho Constitucional, n. ${ }^{\circ} 45$. Según la propia jurisprudencia TJUE, "todo Estado miembro es libre para distribuir, como considere oportuno, las competencias internas y de ejecutar una Directiva por medio de disposiciones de las autoridades regionales o locales. Esta distribución de competencias, sin embargo, no puede dispensarle de la obligación de garantizar que las disposiciones de la Directiva sean fielmente reflejadas en el Derecho interno" STJCE de

18613 de septiembre de 2001. Caso C-417/99. 
nes de niveles sub-estatales) desde diciembre de 2006 (su fecha de publicación en el DOUE aunque el plazo de transposición se extendía hasta el 31 de diciembre de 2009); la Ley catalana de seguridad industrial es de 2008 (por tanto anterior a la estatal) mientras que las leyes estatales son de finales de 2009 (posteriores a la Ley catalana pero anteriores a su Reglamento de desarrollo).

Con todo, vamos a presuponer, sólo como hipótesis de trabajo, que tanto la Directiva misma es legal (de acuerdo con el derecho comunitario) ${ }^{6}$ como que la actividad estatal de transposición de la Directiva es constitucional (de acuerdo con el reparto interno de competencias). Creemos que ambas asunciones no necesariamente son ciertas pero esa es la situación legal en el momento de redactar estas páginas. En otras palabras, no se trata de cuestionar si el Estado ha excedido su ámbito competencial al dictar la normativa armonizadora uniforme para todas las Comunidades autónomas aunque hay poderosos argumentos para pensar que así es7. Tampoco se trata de discutir sobre las bondades de un modelo de protección de la seguridad industrial más intervenido o más cercano a la mera prestación de servicios de control a la industria. Ambos modelos existen y son legítimos de acuerdo con distintas opciones normativas ${ }^{8}$.

De lo que se trata pues en este breve análisis, es precisamente de poner de manifiesto un ejemplo de total incomunicación entre conjuntos normativos (Estado y Comunidades). Nos guste o no, las normas estatales dictadas en transposición DSMI tienen carácter armonizador básico (vide la justificación competencial de las Leyes $17 / 2009$ y 25/2009) y mientras no sean declaradas inconstitucionales mediante la resolución de un conflicto de competencias (no planteado hasta ahora), deberían obligar al conjunto del Estado. Mientras que la doctrina universitaria podemos discurrir sobre los límites competenciales del Estado y la que parece total ignorancia del legis-

6 Para De la Quadra-Salcedo Janini, T. existen argumentos para pensar en la incompetencia comunitaria para dictar la misma DSMI. De la Quadra-Salcedo Janini, T. (2007): “Quo Vadis Bolkenstein? ¿Armonización o mera desregulación de la prestación de servicios” Revista Española de Derecho Europeo n. 22. Igualmente, cfr. Parejo Alfonso, L. (2009b): “La Directiva Bolkenstein y la Ley paraguas: ¿Legitima el fin cualesquiera medios para la reconversión del Estado “autoritativo”?” Revista Española de Derecho Europeo, n. 32 .

7 Muñoz Machado, S. (2009): “Ilusiones y conflictos derivados de la Directiva de Servicios" Revista General de Derecho Administrativo n. 21; París i Domènech, N. y Corretja Torrens, M. (2010): “Aproximació al procés de transposició de la Directiva de Serveis: incidència en el sistema de distribució de competències dissenyat per la CE i l'EAC" Revista d'Estudis Autonómics i Federals n. ${ }^{\circ}$ 10; El CONSELL DE GARANTIES ESTATUTARIES DE CATALUNYA, en su Dictamen 4/2010 de 11 de marzo analiza determinados aspectos de la Ley estatal 25/2009, llegando a la conclusión de que la fundamentación constitucional de los artículos 149.1.18 y 149.1.30 es inconstitucional.

8 Lo hemos analizado ya en Padrós Reig, C. (2010): La Administración Invisible. Dykinson, Madrid. Igualmente, cfr. Canals Ametller, D. (2003): El ejercicio por particulares de funciones de autoridad. Control, inspección y certificación. Comares, Granada; Carrillo Donaire, J.A. (2000): El derecho de la seguridad y de la calidad industrial. Marcial Pons, Madrid; Fernández Ramos, S. (2002): La actividad administrativa de inspección. El régimen juridico general de la función inspectora. Comares. Granada; Nevado-Batalla Moreno, P.T. (2000): La intervención administrativa en la industria: seguridad y control. Comares, Granada; Rivero Ortega, R. (2000): El estado vigilante. Consideraciones jurídicas sobre la función inspectora de la Administración. Tecnos, Madrid. 
lador estatal de la jurisprudencia constitucional largamente elaborada sobre reparto de competencias en materia normación-ejecución del título competencial sobre Industria, los distintos legisladores deberían actuar garantizando la coherencia del conjunto normativo. El Estado adopta un modelo de transposición que choca con los Estatutos de Autonomía y la distribución competencial existente. A su vez, el Decreto catalán 30/2010, de 2 de marzo, queda atrapado entre el ordinario desarrollo reglamentario de la Ley catalana 12/2008 y la incompetencia sobrevenida por el carácter básico de la norma estatal. Parece pues que el Estado autonómico (conflictivo pero armónico) deriva en un peligroso enroque normativo donde las diferencias competenciales se plantean por la vía de los hechos más que por los mecanismos legales de recurso previstos en la LOTC.

\section{LA DIRECTIVA 2006/123/CE DEL PARLAMENTO EUROPEO Y DEL CONSEJO DE 12 DE DICIEMBRE DE 2006, RELATIVA A LOS SERVICIOS EN EL MERCADO INTERIOR ${ }^{9}$}

Con el fin de crear un auténtico mercado interior de servicios en 2010, la DSMI tiene como objetivo facilitar la libertad de establecimiento de los prestadores de servicios en otros Estados miembros y la libertad de prestación de servicios entre los Estados miembros. Esta Directiva también tiene como objetivo ampliar la posibilidad de elección de los destinatarios de los servicios y mejorar la calidad de tales servicios tanto para los consumidores finales (ciudadanos europeos) como para las empresas usuarias de servicios. Como ya hemos indicado, la Directiva se inscribe en el contexto de la llamada "Estrategia de Lisboa" y propone cuatro objetivos fundamentales básicos para conseguir un mercado interior de servicios ${ }^{10}$ :

- facilitar la libertad de establecimiento y la libertad de prestación de servicios en la UE;

- reforzar los derechos de los destinatarios de los servicios en su calidad de usuarios de dichos servicios;

— fomentar la calidad de los servicios;

— establecer una cooperación administrativa efectiva entre los Estados miembros.

La Directiva establece un marco jurídico general para cualquier servicio prestado a cambio de una remuneración económica (salvo los sectores excluidos) teniendo en cuenta, al mismo tiempo, la especificidad de determinadas actividades o profesiones. Por tanto, aparece un principio general de libertad de ejercicio eco-

9 DO L 376 de 27 de diciembre de 2006 p. 0036-0068.

10 www.europa.eu (acceso 15 de mayo de 2010). 
nómico (libertad de acceso o libertad de prestación). Las autorizaciones administrativas para operar sólo podrán justificarse cuando sean proporcionales y necesarias (considerando 54) ${ }^{11}$. El carácter de principio general de la libertad de ejercicio supone, de manera correlativa, la necesidad de interpretar de manera restrictiva las excepciones a la misma. Según el art. 2.2. DSMI, quedan excluidos los servicios siguientes:

- los servicios no económicos de interés general;

- los servicios financieros (como los bancarios, de crédito, de seguros y reaseguros, de pensiones de empleo o individuales, de valores, de fondos de inversión y de pagos);

- los servicios de comunicaciones electrónicas en lo que se refiere a los ámbitos que se rigen por las Directivas en la materia;

— los servicios de transporte, incluidos los portuarios;

- los servicios de las empresas de trabajo temporal;

- los servicios sanitarios;

- los servicios audiovisuales;

- las actividades de juego por dinero;

- las actividades vinculadas al ejercicio de la autoridad pública²;

- determinados servicios sociales (relativos a la vivienda social, la atención a los niños y el apoyo a personas necesitadas);

— los servicios de seguridad privados;

- los servicios prestados por notarios y agentes judiciales designados mediante un acto oficial de la Administración.

11 Ello supone nada más y nada menos que la introducción de un artículo 39bis en la Ley 30/1992, a tenor del cual, la Administración debe motivar la necesidad del ejercicio de la potestad autorizatoria y justificar su adecuación para alcanzar los fines de interés público que se persiguen. Vide ut infra.

12 Lo que deba entenderse por ejercicio de la autoridad pública no queda definido sino que se efectúa una remisión al art. 45 del TCE. Según esta disposición, “Las disposiciones del presente capítulo (libertad de establecimiento) no se aplicarán, en lo que respecta al Estado miembro interesado, a las actividades que, en dicho Estado, estén relacionadas, aunque sólo sea de manera ocasional, con el ejercicio del poder público. El Consejo, por mayoría cualificada y a propuesta de la Comisión, podrá excluir determinadas actividades de la aplicación de las disposiciones del presente capítulo." (paréntesis añadido). Versión consolidada del TCE (Versión consolidada) Diario Oficial n C 325 de 24 diciembre 2002, en vigor al aprobarse la DSMI. 
La Directiva no debería, en principio, afectar a la libertad que ostentan los Estados miembros para definir los servicios de interés económico general. De acuerdo con el ordenamiento comunitario, es el legislador nacional quien debe encargar de forma concreta y precisa a uno o varios operadores la realización de esas actividades de interés general y el modo de financiarlas. En principio, pues, la Directiva dejaría a salvo este reducto de soberanía estatal. Sin embargo, a nadie se le escapa que la organización y financiación de los servicios públicos (y por ello reservados o excluidos de la normal competencia en el mercado), es objeto de severo escrutinio por parte del Tribunal de Justicia y del Tribunal General.

La Directiva, no sólo dedica sus esfuerzos a garantizar la eliminación de las barreras legales de entrada en las actividades económicas sino que impone también que los Estados miembros verifiquen (“cribado") y, según proceda, simplifiquen los procedimientos y trámites aplicables al acceso a una actividad de servicios y a su ejercicio. Por ello, la DSMI podría definirse como liberalizadora y desburocratizadora al mismo tiempo ${ }^{13}$.

Con ello se prevé eliminar los obstáculos jurídicos y administrativos al desarrollo de las actividades de servicios. Sin embargo, desde el punto de vista de la normatividad, algunas de las formulaciones de la Directiva parecen algo infantiles. Así, si se acude a la dicción del art. 5.1. se establece que "cuando los procedimientos y formalidades estudiados de conformidad con este apartado no sean lo suficientemente simples, los Estados miembros los simplificarán”. No hay ningún elemento definitorio de lo que sea un procedimiento "suficientemente simple" ni de lo que deba suponer la simplificación administrativa, más allá de una acepción vulgar de la misma.

En todo lo relativo a los servicios, el enfoque comunitario es doble. De una parte existe la posibilidad de prestar servicios mediante la creación de un establecimiento en el país (libertad de establecimiento); por otra parte, existen servicios que pueden prestarse a distancia de manera transfronteriza (libertad de prestación). La DSMI presenta disposiciones en ambos sentidos.

a) Para facilitar la libertad de establecimiento, la Directiva prevé (Capítulo III, arts. 9 a 15) los siguientes elementos:

- obligación de evaluar la compatibilidad de los regímenes de autorización, basándose en los principios de no discriminación y proporcionalidad, y de respetar determinados principios relativos a las condiciones y procedimientos de autorización aplicables a las actividades de servicios. De hecho, merece la pena enumerar todos los criterios en los que ha de basarse una autorización para limitar la facultad de apreciación de las autoridades nacionales:

13 En particular, el Capítulo II de la Directiva (arts. 5 a 8) prevé tanto la creación de ventanillas únicas en las que un prestador podrá realizar todos los trámites necesarios para ejercer su actividad como la obligación de posibilitar la realización de estos procedimientos por vía electrónica. 


\section{CUADRO 1}

Características de los criterios de autorización (art. 10.1.)

- No ser discriminatorios.

- Estar justificados por una razón imperiosa de interés general.

- Ser proporcionados al objetivo de interés general.

- Ser claros e inequívocos.

- Ser objetivos.

- Ser hechos públicos con antelación.

- Ser transparentes y accesibles.

- La prohibición de determinados requisitos jurídicos restrictivos que persisten en la legislación de determinados Estados miembros y que no pueden justificarse, como las exigencias de nacionalidad.

\section{CUADRO 2}

\section{Prohibición de requisitos (art. 14.)}

(1) Requisitos discriminatorios basados directa o indirectamente en la nacionalidad o, en lo que se refiere a las sociedades, el domicilio social, y, especialmente: a) requisito de nacionalidad para el prestador, su personal, las personas que posean capital social o los miembros de los órganos de gestión y supervisión; b) requisito de residir en el territorio nacional para el prestador, su personal, las personas que posean capital social o los miembros de los órganos de gestión y supervisión.

(2) Prohibición de estar establecido en varios Estados miembros o de estar inscrito en los registros o colegios o asociaciones profesionales de varios Estados miembros.

(3) Limitaciones de la libertad del prestador para elegir entre un establecimiento principal o secundario $y$, especialmente, la obligación de que el prestador tenga su establecimiento principal en el territorio nacional, o limitaciones de la libertad de elección entre establecimiento en forma de agencia, de sucursal o de filial.

(4) Condiciones de reciprocidad con el Estado miembro en el que el prestador tenga ya su establecimiento, con excepción de las previstas en los instrumentos comunitarios en materia de energía.

(5) Aplicación, caso por caso, de una prueba económica consistente en supeditar la concesión de la autorización a que se demuestre la existencia de una necesidad económica o de una demanda en el mercado, a que se evalúen los efectos económicos, posibles o reales, de la actividad o a que se haga una apreciación de si la actividad se ajusta a los objetivos de programación económica fijados por la autoridad competente; esta prohibición no afectará a los requisitos de planificación que no sean de naturaleza económi$\mathrm{ca}$, sino que defiendan razones imperiosas de interés general.

(6) Intervención directa o indirecta de competidores, incluso dentro de órganos consultivos, en la concesión de autorizaciones o en la adopción de otras decisiones de las autoridades competentes, con excepción de los colegios profesionales y de las asociaciones y organismos que actúen como autoridad competente; esta prohibición no afectará a la consulta de organismos como las cámaras de comercio o los interlocutores sociales sobre asuntos distintos a las solicitudes de autorización individuales, ni a una consulta del público en general. 


\section{CUADRO 2 (cont.)}

Prohibición de requisitos (art. 14.)

(7) Obligación de constituir un aval financiero, de participar en él o de suscribir un seguro con un prestador u organismo establecido en el territorio nacional. Ello no afectará a la posibilidad de los Estados miembros de exigir garantías de un seguro o financieras como tales, ni a los requisitos relativos a la participación en fondos colectivos de compensación, por ejemplo, para miembros de colegios u organizaciones profesionales.

(8) Obligación de haber estado inscrito con carácter previo durante un período determinado en los registros existentes en el territorio nacional o de haber ejercido previamente la actividad durante un período determinado en dicho territorio.

- La obligación de evaluar la compatibilidad de otros requisitos jurídicos basándose en los principios de no discriminación y proporcionalidad.

\section{CUADRO 3}

\section{Requisitos no discriminatorios objeto de evaluación (art. 15)}

Límites cuantitativos o territoriales y, concretamente, límites fijados en función de la población o de una distancia geográfica mínima entre prestadores.

Requisitos que obliguen al prestador a constituirse adoptando una forma jurídica particular.

Requisitos relativos a la posesión de capital de una sociedad.

Requisitos distintos de los relativos a las materias contempladas en la Directiva 2005/36/CE o de los previstos en otros instrumentos comunitarios y que sirven para reservar el acceso a la correspondiente actividad de servicios a una serie de prestadores concretos debido a la índole específica de la actividad.

Prohibición de disponer de varios establecimientos en un mismo territorio nacional.

Requisitos que obliguen a tener un número mínimo de empleados.

Tarifas obligatorias mínimas y/o máximas que el prestador debe respetar.

Obligación de que el prestador realice, junto con su servicio, otros servicios específicos.

b) A su vez, para facilitar la libertad de prestación temporal de servicios transfronterizos la Directiva (Capítulo IV, arts. 16 a 21), establece que los Estados miembros deben garantizar en su territorio el libre acceso a la actividad de servicios y su libre ejercicio. El Estado miembro al que el prestador de servicios se desplace sólo podrá imponer el respeto de sus propios requisitos a condición de que sean no discriminatorios, resulten proporcionados y estén justificados por razones de orden público, seguridad pública, salud pública o protección del medio ambiente. 


\section{CUADRO 4}

Prohibición de requisitos (art. 16.2.)

Obligación de que el prestador esté establecido en el territorio nacional.

Obligación de que el prestador obtenga una autorización concedida por las autoridades competentes nacionales, incluida la inscripción en un registro o en un colegio o asociación profesional que exista en el territorio nacional, salvo en los casos previstos en la presente Directiva o en otros instrumentos de Derecho comunitario.

Prohibición de que el prestador se procure en el territorio nacional cierta forma o tipo de infraestructura, incluida una oficina o un gabinete, necesaria para llevar a cabo las correspondientes prestaciones.

Aplicación de un régimen contractual particular entre el prestador y el destinatario que impida o limite la prestación de servicios con carácter independiente.

Obligación de que el prestador posea un documento de identidad específico para el ejercicio de una actividad de servicios, expedido por las autoridades competentes.

Requisitos sobre el uso de equipos y material que forman parte integrante de la prestación de servicios, con excepción de los necesarios para la salud y la seguridad en el trabajo.

Las restricciones de la libre circulación de servicios contempladas en el artículo 19.

La Directiva también prevé un determinado número de excepciones importantes a este principio, como por ejemplo en materia de calificaciones profesionales, desplazamiento de trabajadores y en el caso de los servicios de interés económico general.

\section{CUADRO 5}

Excepciones a la libre prestación de servicios (art. 17)

1) A los servicios de interés económico general que se presten en otro Estado miembro, a saber, entre otros:

a) los servicios postales a los que se refiere la Directiva 97/67/CE del Parlamento Europeo y del Consejo, de 15 de diciembre de 1997, relativa a las normas comunes para el desarrollo del mercado interior de los servicios postales de la Comunidad y la mejora de la calidad del servicio

b) los servicios del sector eléctrico a que se refiere la Directiva 2003/54/CE del Parlamento Europeo y del Consejo, de 26 de junio de 2003, sobre normas comunes para el mercado interior de la electricidad

c) los servicios del sector del gas a que se refiere la Directiva 2003/55/CE del Parlamento Europeo y del Consejo, de 26 de junio de 2003 , sobre normas comunes para el mercado interior del gas natural

d) los servicios de distribución y suministro de agua y los servicios de aguas residuales;

e) el tratamiento de residuos.

2) A las materias que abarca la Directiva 96/71/CE.

3) A las materias a las que se refiere la Directiva 95/46/CE del Parlamento Europeo y del Consejo, de 24 de octubre de 1995, relativa a la protección de las personas físicas en lo que respecta al tratamiento de datos personales y a la libre circulación de estos datos. 


\section{CUADRO 5 (cont.)}

\section{Excepciones a la libre prestación de servicios (art. 17)}

4) A las materias a las que se refiere la Directiva 77/249/CEE del Consejo, de 22 de marzo de 1977, dirigida a facilitar el ejercicio efectivo de la libre prestación de servicios por los abogados.

5) A las actividades de cobro de deudas por vía judicial.

6) A las materias a las que se refiere el título II de la Directiva 2005/36/CE, incluidos los requisitos de los Estados miembros en que se presta el servicio por los que se reserva una actividad a una determinada profesión.

7) A las materias a las que se refiere el Reglamento (CEE) no 1408/71.

8) En relación con los trámites administrativos relativos a la libre circulación de personas y su residencia, a las materias reguladas por la Directiva 2004/38/CE, en la que se establecen los trámites administrativos de las autoridades competentes del Estado miembro en el que se presta el servicio que son de obligatorio cumplimiento por parte de los beneficiarios.

9) En relación con los nacionales de terceros países que se desplazan a otro Estado miembro en el contexto de la prestación de un servicio, a la posibilidad de los Estados miembros de imponer la obligación de visado o de permiso de residencia a los nacionales de terceros países que no disfruten del régimen de equivalencia mutua previsto en el artículo 21 del Convenio de aplicación del Acuerdo de Schengen, de 14 de junio de 1985, relativo a la supresión gradual de los controles en las fronteras comunes, o a la de imponer a los nacionales de terceros países la obligación de presentarse a las autoridades competentes del Estado miembro en el que se presta el servicio en el momento de su entrada o posteriormente.

10) Por lo que se refiere al transporte de residuos, a los asuntos cubiertos por el Reglamento (CEE) no 259/93 del Consejo, de 1 de febrero de 1993, relativo a la vigilancia y al control de los traslados de residuos en el interior, a la entrada y a la salida de la Comunidad Europea.

11) A los derechos de autor y derechos afines, los derechos contemplados en la Directiva 87/54/CEE del Consejo, de 16 de diciembre de 1986, sobre la protección jurídica de las topografías de los productos semiconductores [35] y en la Directiva 96/9/CE del Parlamento Europeo y del Consejo, de 11 de marzo de 1996, sobre la protección jurídica de las bases de datos [36], y los derechos de propiedad industrial.

12) A los actos para los que se exija por ley la intervención de un notario.

13) A los asuntos cubiertos por la Directiva 2006/43/CE del Parlamento Europeo y del Consejo, de 17 de mayo de 2006, relativa a la auditoría legal de las cuentas anuales y de las cuentas consolidadas.

14) A la matriculación de vehículos objeto de un arrendamiento financiero en otro Estado miembro.

15) A las disposiciones aplicables a las obligaciones contractuales y extracontractuales, incluida la forma de los contratos, determinadas de conformidad con las normas del De-

194 recho internacional privado. 
Finalmente, las disposiciones de la DSMI prevén también de manera bastante exhaustiva, la cuestión de la calidad de los servicios y el aseguramiento de la responsabilidad profesional así como la protección de los usuarios de servicios, que pese a su indudable interés escapan del ámbito de este análisis.

Una nueva cultura administrativa como la presentada por la DSMI requiere sin lugar a dudas de una nueva organización administrativa o la adaptación de la existente a una cooperación administrativa efectiva entre Estados miembros ${ }^{14}$. Por ello, y con la idea de facilitar el establecimiento y la libre circulación de los servicios en la Unión Europea, la Directiva establece una obligación legal vinculante para los Estados miembros de cooperar con las autoridades de otros Estados miembros para garantizar un control eficaz de las actividades de servicios en la Unión y, al mismo tiempo, evitar una multiplicación de los controles; también se ha creado un mecanismo de alerta y evaluación mutua entre Estados miembros mediante un sistema electrónico de intercambio de información entre Estados miembros.

Toda esta larga descripción contextual nos obliga a concluir que, si bien la afectación a los ordenamientos administrativos nacionales es fenomenal, no se obliga directamente a la "depublicatio" de servicios de interés general. También se permite la exclusión del ámbito de la DSMI de "las actividades vinculadas al ejercicio de la autoridad pública" que constituirá el verdadero caballo de batalla en relación a las entidades encargadas de controlar la normativa de seguridad industrial como veremos más adelante. Se producirá con seguridad una fuerte asimetría entre Estados en la aplicación de la DSMI. Además, al igual que ocurre con la prestación de sectores regulados, se sujeta a fuertes restricciones a los Estados que abran sus mercados mientras que se dejan a salvo ciertos modelos de prestación ${ }^{15}$. Sea como fuere, los servicios prestados a las empresas en el campo de la seguridad industrial no tienen una regulación específica en la DSMI, lo cual deja cierto margen de maniobra a los Estados para considerarlos como ejercicio de una potestad pública de ordenación (mediante personas interpuestas en la mayoría de los casos) o simples actividades de prestación de servicios a las empresas.

\section{LA TRANSPOSICIÓN DE LA DSMI EN ESPAÑA}

Una operación normativa de tanta trascendencia como la implementación en los ordenamientos nacionales de la Directiva 2006/123/CE con su profundo calado y carácter horizontal ha impulsado a la propia Comisión Europea a elaborar un Manual sobre la Transposición de la Directiva de Servicios ${ }^{16}$. El texto es suficientemente rico y

14 González García, J.V. (2009): “La transposición de la Directiva de servicios: aspectos normativos y organizativos en el Derecho español” Revista Española de Derecho Europeo, n. 32.

15 Vide lo que sucede con el sector de la energía eléctrica y la posición de la empresa francesa EdF.

16 http://ec.europa.eu/internal_market/services/docs/services-dir/guides/handbook_es.pdf · (último acceso 1 mayo de 2010). Entre la doctrina también Rivero Ortega, R. (2009): “Antecedentes, principios generales y repercusiones administrativas de la Directiva de Servicios: problemas de su transposición en España", Revista de Estudios Locales, n. 122. 
complejo como para merecer un análisis detallado, sin embargo, nos interesan instrumentalmente dos aspectos: la definición de servicio y los servicios excluidos por razón de implicar ejercicio de autoridad.

a) Para empezar, es importante comprender el "concepto de servicio" y el alcance de las actividades que engloba. Dicho concepto, de conformidad con el Tratado CE y la jurisprudencia vinculada del TJCE, se define de un modo amplio (art. 4.1. TCE). Engloba toda actividad económica por cuenta propia realizada normalmente a cambio de una remuneración, como se recoge en el artículo 50 del Tratado CE. Así, con arreglo al significado previsto en el Tratado CE y en la Directiva de servicios, para que una actividad constituya un "servicio" ha de realizarse por cuenta propia, es decir, ha de ser realizada por un prestador (que puede ser persona física o jurídica) al margen de un contrato de trabajo ${ }^{17}$. Además, debe realizarse normalmente a cambio de una remuneración; en otras palabras, ha de ser de naturaleza económica. Estas condiciones deben evaluarse caso por caso en cada actividad ${ }^{18}$. El mero hecho de que una actividad sea realizada por el Estado, por un órgano de éste o por una organización sin ánimo de lucro no significa que no constituya un servicio conforme al significado recogido en el Tratado CE y en la Directiva de servicios ${ }^{19}$. Más bien, de conformidad con la jurisprudencia del TJCE, "la característica esencial de la remuneración reside en el hecho de que esta última constituye la contrapartida económica de la prestación que se discute" ${ }^{20}$. Es irrelevante que la remuneración sea abonada por el destinatario del servicio o por un tercero ${ }^{21}$. En cualquier caso, cabe señalar que el TJCE, en el contexto de los servicios de educación prestados en el marco del sistema de educación nacional, declaró que las matrículas -que los alumnos o sus padres deben abonar en ocasiones para contribuir en cierta medida a sufragar los costes de funcionamiento del mismo- no constituyen como tales una remuneración si el sistema se financia de todos modos esencialmente mediante fondos públicos ${ }^{22}$.

En consecuencia, la jurisprudencia deja claro que un servicio puede ser igualmente económico si es prestado por el Estado. No queda, sin embargo, tan claro si un servicio prestado por una entidad privada puede considerarse una función pública (cuestión clave en el análisis de la inspección certificación y homologación de productos e instalaciones industriales).

\footnotetext{
17 sentencia de 12 de diciembre de 1974, Walrave, asunto 36/74.

18 ello conlleva un enorme casuismo y atribuye al TJUE un papel de motor de la integración europea no siempre acorde con su carácter de órgano judicial.

19 sentencia de 11 de abril de 2000, Deliège, asuntos acumulados C-51/96 y C-191/97.

20 sentencia de 27 de septiembre de 1988, Humbel, asunto C-263/86.

21 Sentencia de 26 de abril de 1988, Bond van Adverteerders, asunto 352/85; sentencia de 13 de mayo de 2003, Müller Fauré, asunto C-385/99; sentencia de 12 de julio de 2001, Smits y Peerbooms, asunto C-157/99.

22 sentencia de 7 de diciembre de 1993, Wirth, asunto C-109/92. Educación, Sanidad o Servicios sociales se encontrarían excluidos al tratarse de "servicios no económicos" del art. 2.2. DSMI.
} 
En definitiva, los Estados miembros deben garantizar que las normas de la DSMI se apliquen a una amplia gama de actividades, ya se presten a empresas o a consumidores. Sin ánimo de exhaustividad, pueden mencionarse como ejemplos de servicios contemplados en la Directiva los siguientes: las actividades de la mayoría de las profesiones reguladas ${ }^{23}$ (como asesores jurídicos y fiscales, arquitectos, ingenieros, contables, peritos); los servicios de los autónomos; los servicios a empresas (como los de mantenimiento de oficinas, consultoría de gestión, organización de eventos, cobro de deudas, publicidad y selección de personal); las tareas de distribución (incluido el comercio minorista y mayorista de bienes y servicios); los servicios en el campo del turismo (como los que prestan las agencias de viaje); los servicios de ocio (como los que prestan centros deportivos y parques de atracciones); los servicios de construcción, los de instalación y mantenimiento de equipos; los servicios de información (como portales de Internet, agencias de noticias, editoriales, actividades de programación informática); los servicios de alojamiento y restauración (como los que prestan hoteles, restaurantes, empresas de comidas a domicilio); los servicios en el área de la formación y la educación; los servicios de alquiler (incluido el alquiler de automóviles) y de leasing; los servicios inmobiliarios; los de certificación y verificación, los servicios domésticos (como los de limpieza, cuidadores de menores y jardinería), etc.

A juicio de la Comisión, pues, los servicios de certificación y verificación quedan incluidos dentro del ámbito de aplicación de la DSMI y por ello sujetos a la libertad de establecimiento y prestación.

b) A pesar de la amplitud de la definición de servicio que adopta la Comisión Europea, en la materia objeto de nuestro estudio, es decir, la normativa de seguridad industrial y su control por parte de entidades colaboradoras, puede tener especial relevancia la excepción relativa a los servicios vinculados al ejercicio de la autoridad pública (art. 2.2. DSMI). La exclusión consignada en el artículo 2, apartado 2, letra i), refleja lo dispuesto en el artículo 45 del Tratado CE, con arreglo al cual las actividades vinculadas al ejercicio de la autoridad pública (aunque sólo sea de manera ocasional) no se someten a las disposiciones relativas a la libertad de establecimiento y la libertad de prestación de servicios. Esta exclusión, de conformidad con la jurisprudencia del TJCE, sólo abarca actividades específicas, no profesiones o sectores enteros de actividad ${ }^{24}$.

La determinación de si ciertas actividades están vinculadas de manera directa o específica al ejercicio de la autoridad pública no es una cuestión que pueda decidir

23 En este contexto, debe quedar claro que siguen siendo aplicables los instrumentos comunitarios vigentes, como, en el caso de las profesiones reguladas, la Directiva 2005/36/CE del Parlamento Europeo y del Consejo, de 7 de septiembre de 2005, relativa al reconocimiento de cualificaciones profesionales (DO L 255 de 30.9.2005, p. 22).

24 Sentencia de 9 de marzo de 2000, Comisión contra. Bélgica, asunto C-355/98; véase asimismo la sentencia de 29 de octubre de 1998, Comisión contra España, asunto C-114/97; sentencia de 13 de julio de 1993, Thijssen, asunto C-42/92, y la sentencia de 21 de junio de 1974, Reyners, asunto 2/74. 
unilateralmente un Estado miembro, sino que ha de evaluarse con arreglo a los criterios generales establecidos por el TJCE. Así, el mero hecho de que un Estado miembro considere una actividad como ejercicio de autoridad pública, o que sea desempeñada por él, por un órgano administrativo o por una entidad a la que se hayan asignado tareas públicas, no significa que tal actividad encaje en lo dispuesto en el artículo 45 del Tratado CE. Cuando se enfrenten a casos en los que tengan que evaluar si una actividad de servicios cae dentro del artículo 45 del Tratado CE, con lo que quedaría excluida de la Directiva de servicios, los Estados miembros deberán tener en cuenta el ámbito de aplicación ciertamente restrictivo que el TJCE ha reconocido al referido artículo.

Efectivamente, el TJCE ha declarado que el artículo 45 -y la correlativa excepción de las actividades que impliquen ejercicio de autoridad pública- no atañe a las actividades de índole meramente auxiliar y preparatoria en relación con el ejercicio de la autoridad pública (sentencia de 13 de julio de 1993, Thijssen, asunto 42/92) ni a las actividad de naturaleza meramente técnica, como las que conciernen al diseño, la programación y la operación de sistemas de proceso de datos (sentencia de 5 de diciembre de 1989, Comisión contra Italia, asunto 3/88). Por otra parte, varias actividades de servicio han sido expresamente ya excluidas del ámbito del artículo 45 del Tratado CE por el TJCE: la actividad de los abogados (sentencia de 21 de junio de 1974, Reyners, asunto 2/74); las actividades de las empresas de seguridad ${ }^{25}$; las actividades de auditores autorizados ante entidades aseguradoras (sentencia de 13 de julio de 1993, Thijssen, asunto C-42/92); las actividades de diseño, programación y operación de sistemas de proceso de datos (sentencia de 5 de diciembre de 1989, Comisión contra Italia, asunto 3/88); las actividades Ilevadas a cabo en el marco de contratos relativos a los locales, suministros, instalaciones, mantenimiento, funcionamiento y transmisión de datos necesarios para la gestión de una lotería (sentencia de 26 de abril de 1994, Comisión contra Italia, asunto (-272/91) ${ }^{26}$.

De lo antedicho, podría pensarse que la doctrina de la Comisión y del Tribunal distinguen entre aquellos servicios auxiliares a la industria (certificación y verificación), de aquellos que impliquen propiamente una facultad inspectora ${ }^{27}$. Los primeros estarían englobados dentro del concepto de servicio y se beneficiarían de las libertades de la DSMI, mientras que los segundos constituirían ejercicio de autoridad pública y quedarían excluidos.

Un caso interesante se plantea a propósito de la naturaleza de los servicios de vigilancia portuaria y es resuelto por la STJCEE de 18 de marzo de 1997 (Asunto C-343/95).

25 Sentencias de 31 de mayo de 2001, Comisión contra Italia, asunto C-283/99; sentencia de 9 de marzo de 2000, Comisión contra Bélgica, asunto C-355/98; sentencia de 26 de enero de 2006, Comisión contra España, asunto C-514/03.

26 Respecto de estos últimos, si bien las actividades auxiliares de las loterías estarían comprendidas dentro de los servicios liberalizados, no la actividad principal de organizar juegos y apuestas a cambio de dinero (excluidos expresamente en la delimitación negativa del art. 2.2.).

27 El deslinde entre unos y otros no es, sin embargo, una tarea nada fácil y queda sujeta a la calificación que hagan las propias Administraciones nacionales como de hecho veremos. 
El asunto refiere a la resolución de una cuestión prejudicial en un pleito que enfrentaba a una empresa transportista (Calì) y otra empresa (SEPG) que presta servicios de prevención medioambiental del puerto de Génova. El Reglamento del Puerto creó un servicio obligatorio de vigilancia e intervención rápida destinado a proteger el dominio marítimo contra eventuales contaminaciones consecuencia de vertidos accidentales de hidrocarburos. El reglamento en cuestión define dicho servicio de prevención como el ejercicio de una vigilancia constante de las aguas, debido a la presencia de buques cisterna que atracan o están amarrados en los muelles, a fin de detectar inmediatamente posibles riesgos de vertidos de hidrocarburos o de otras sustancias contaminantes. El puerto de Génova otorgó una concesión exclusiva a la empresa Servizi Ecologici Porto di Genova (SPEG) y este título le permitía aplicar una tarifa a los buques que utilizaban las instalaciones de la terminal petrolera.

A los efectos de determinar la aplicabilidad de la normativa europea sobre competencia, opina el TJCE que no importa si el Estado actúa directamente a través de un órgano que forme parte de la Administración Pública o a través de una entidad a la que haya concedido derechos especiales o exclusivos. Lo relevante para efectuar la distinción entre los dos supuestos mencionados, es examinar la naturaleza de las actividades que ejercen la empresa pública o la entidad a la que el Estado ha concedido derechos especiales o exclusivos. Pues bien, según el pronunciamiento del Tribunal, la vigilancia anticontaminación que los SEPG deben llevar a cabo en el puerto petrolero de Génova constituye una misión de interés general que forma parte de las funciones esenciales del Estado en materia de protección del medio ambiente en el dominio marítimo. De este modo, tal actividad de vigilancia, por su naturaleza, por su objeto y por las normas a las que está sujeta, se vincula al ejercicio de prerrogativas relativas a la protección del medio ambiente, que son prerrogativas típicas del poder público. No tienen un carácter económico que justifique la aplicación de las normas sobre la competencia del Tratado ${ }^{28}$.

Recientemente, cabe hacer mención a la STJCEE de 22 de octubre de 2009 (As. C-438/08 Comisión contra República Portuguesa) que tiene por objeto un recurso de incumplimiento respecto a la libertad de establecimiento de la actividad de inspección técnica de vehículos. Efectivamente, la cuestión relevante de la sentencia reside precisamente en saber si el hecho que Portugal imponga la concesión administrativa como modo de prestar el servicio de ITV (junto con otras restricciones que no nos interesan ahora $)^{29}$ constituye una restricción injustificada a la libertad de establecimiento. El razonamiento del Tribunal debe encuadrarse dentro del marco de neutralidad organizativa que prevé el art. 2 de la Directiva 96/96/CE, del Consejo de 20 de diciembre de 1996: “La inspección técnica prevista en la presente Directiva deberá ser efectuada por el Estado o por un organismo público encargado por el Estado de

28 Véase la sentencia de 19 de enero de 1994 SAT Fluggesellschaft, C-364/92, Rec. p. I-43 apartado 30 .

29 Capital social mínimo de las entidades; objeto social de las empresa de inspección; régimen de incompatibilidad de los gerentes, socios y administradores. 
este cometido o por organismos o establecimientos designados por el Estado y que actúen bajo su vigilancia directa, que podrán ser organismos privados debidamente autorizados para ello. En los casos en que un establecimiento encargado de la inspección técnica también se dedique a la reparación de vehículos, los Estados miembros velarán [muy especialmente] por el mantenimiento de la objetividad y de la alta calidad de la inspección técnica”.

Por lo tanto, el marco armonizador europeo deja (mejor dicho, dejaba) abiertas las puertas a los Estados para que utilicen tanto la prestación directa, como la indirecta como la explotación por privados. Entonces, lo que deberá dilucidar el Tribunal es si la actividad de ITV es de tal naturaleza pública que permite su sustracción a las reglas de mercado (posición de Portugal) o por el contrario, la concesión resulta en un obstáculo injustificado para el ejercicio de una actividad económica (en sintonía con las disposiciones DSMI). Al respecto, determina la sentencia que los requisitos controvertidos impuestos por la normativa portuguesa para el acceso a la actividad de inspección técnica de los vehículos constituyen un obstáculo a la libertad de establecimiento. Por tanto, la sujeción de los operadores de ITV a un requisito de entrada como es la obtención de una concesión administrativa supone un obstáculo a las libertades comunitarias.

¿Puede justificarse dicho obstáculo habida cuenta de la importancia de la función que desarrollan los operadores ITV en la garantía de la seguridad del tráfico o más generalmente en desarrollo de una prerrogativa de poder público? La respuesta del Tribunal es contundente: las funciones ITV son exclusivamente de carácter técnico y, por consiguiente, ajenas al ejercicio del poder público. La decisión de certificar o no certificar la inspección técnica se limita, en esencia, a constatar los resultados de la inspección, por lo que, de una parte, carece de la autonomía decisoria propia del ejercicio de las prerrogativas de poder público, y, por otra parte, se adopta en el marco de una supervisión estatal directa.

Desvelado pues por la sentencia el carácter técnico de la actividad y la inexistencia de prerrogativas públicas en su ejercicio (falta de autonomía decisoria, es decir, carácter reglado de la resolución de conceder o no el distintivo ITV; supervisión pública; inexistencia de facultades coercitivas) resulta claro que someter a los operadores a la obtención de un título habilitante como la concesión administrativa no resulta acorde con la proporcionalidad y necesariedad que requieren las excepciones a la libertad de establecimiento. El Tribunal pues declara que el sistema concesional de acceso a las ITV incumple el Tratado ${ }^{30}$.

Como puede fácilmente apreciarse la misma justificación que se argumentó en el caso del puerto de Génova, podría aplicarse a este caso y considerar que los servicios

30 El TJCE resuelve de un plumazo toda la serie jurisprudencial donde nuestro Tribunal Supremo hacía mil equilibrios para encontrar un encuadre doctrinal a la ITV. Vide STS de 13 de octubre de 1997; STS de 7 de mayo de 1999 y STS de 17 de noviembre de 2000. cfr. Arana García, E. (1999): “Naturaleza Jurídica de la actividad de Inspección Técnica de Vehículos”, Revista Vasca de Administración Pública, n. 54. 
de inspección técnica de vehículos constituyen un elemento esencial de la política pública de protección de la seguridad vial y por ello una parte de las prerrogativas típicas del poder público. Salta a la vista, pues, un cierto casuismo del TJUE. Pero más allá de ello, lo cierto es que no bastará con que un Estado miembro defina un determinado servicio como dentro de su ámbito de prerrogativas sino que ésta exclusión de la libertad de prestación deberá superar el examen del Tribunal europeo ${ }^{31}$. Si extrapolamos el caso de las ITV a otros sectores análogos en materia de control de la seguridad industrial resulta que los elementos determinantes para calificar la actividad como administrativa (ejercicio de autoridad) serán:

— si las funciones que ejercen las entidades son exclusivamente de carácter técnico

— si las inspecciones simplemente constatan elementos fácticos

- si las entidades inspectoras gozan o carecen de autonomía decisoria propia del poder público

- si las certificaciones son adoptadas en el marco de una supervisión estatal directa

Teniendo en cuenta el contexto proporcionado por la jurisprudencia del Tribunal, España ha acometido la transposición de la Directiva mediante la Ley 17/2009, de 23 de noviembre, sobre el libre acceso a las actividades de servicios y su ejercicio ${ }^{32}$.

Para lo que a nosotros interesa, la Ley 17/2009 sigue de manera bastante mecánica y acrítica la estructura y los contenidos de la DSMI. La actividad de transposición al ordenamiento interno de la Directiva se ha basado fundamentalmente en el texto normativo europeo sin demasiadas innovaciones. En las excepciones, existen pequeños detalles de poca trascendencia. Así, al excluir los servicios sanitarios, la Ley española hace mención expresa de los servicios farmacéuticos. En cuanto a la excepción de los servicios que impliquen ejercicio de autoridad, el art. 2.2. apartado i) restringe el concepto comunitario del artículo 45 del Tratado a los notarios y registradores ${ }^{33}$. Una cosa es que una actividad pueda suponer el ejercicio delegado de funciones públicas de autoridad y otra distinta es el concepto de la fe pública notarial o registral ${ }^{34}$. De acuerdo con la dicción legal de la Ley 17/2009, las actividades de control industrial o ambiental que puedan suponer ejercicio de autoridad (por ejemplo, órdenes de cierre inmediato o de suspensión de actividad), no quedarían expresamente excluidas, cuando este no parece ser el espíritu del derecho comunitario.

31 ello reduce de manera notable el ámbito de soberanía autoorganizativa de las Administraciones públicas de los Estados.

32 BOE n. 283 , de 24 de noviembre de 2009.

33 Aunque utiliza el término "en particular" parece que la mención a los notarios y registradores aclara el término más general de "ejercicio de autoridad" y por ello lo restringe a ese aspecto concreto.

34 De hecho, no es casual que en el texto de la DSMI estas dos excepciones se encuentren separadas (autoridad pública en art. 2.2.i; mientras que fe pública en art. 2.2.I.). 
Tampoco en la definición de las razones imperiosas de interés general la Ley se aparta de la doctrina comunitaria, y existe una identidad total entre el art. 4 apartado 8 DSMI y el art. 3.11 de la Ley $17 / 2009$.

El régimen de las autorizaciones administrativas de acceso a las actividades económicas se convierte en extremadamente rígido. Así, por disposición del art. 6 de la Ley estatal, los procedimientos y trámites para la obtención de las autorizaciones a que se refiere esta Ley deberán tener carácter reglado, ser claros e inequívocos, objetivos e imparciales, transparentes, proporcionados al objetivo de interés general y darse a conocer con antelación. Igualmente deben poder gozar del régimen de silencio administrativo positivo y de la posibilidad de recurso. Todo ello desemboca en la incorporación de un art. 39bis de la Ley 30/1992 (LRJAP), que por virtud de la Ley 25/2009 (Ley ómnibus), quedará redactado de la siguiente forma:

"Las Administraciones públicas que en ejercicio de sus respectivas competencias establezcan medidas que limiten el ejercicio de derechos individuales o colectivos o exijan el cumplimiento de requisitos para el desarrollo de una actividad deberán elegir la medida menos restrictiva, motivar su necesidad para la protección del interés público así como justificar su adecuación para lograr los fines que se persiguen, sin que en ningún caso se produzcan diferencias de trato discriminatorias" 35 .

La Ley española ha optado por una transposición "de máximos" de la norma comunitaria ${ }^{36}$. Esta no era la única opción pero ha sido la legítimamente elegida por las Cortes Generales. Otros ordenamientos, como el alemán o el francés se han limitado a la creación de servicios de información o simplificación para los trámites administrativos de las empresas sin afectar de manera global los mecanismos administrativos de autorización previa ${ }^{37}$. Sea como fuere, la Ley 17/2009 tiene carácter básico pues se dicta en base a la competencia estatal de planificación de la actividad económica (art. 149.1.13) y de bases del régimen jurídico de las Administraciones públicas (art. 149.1.18)38.

35 Fernández Rodríguez destaca como la disposición ahora incorporada en la Ley 30/1992 con gran etiqueta de modernidad existía ya en el Reglamento de Servicios de las Corporaciones Locales de 1955. En su artículo 6 se prevé que la intervención municipal será congruente con los motivos y fines que la motiven y que si fueren varios los instrumentos reguladores posibles, se elegirá el menos restrictivo de la libertad individual” Fernández Rodríguez, T.R. (2007): “Un nuevo Derecho Administrativo para el mercado interior europeo" Revista Española de Derecho Europeo n. 22, p. 192.

36 cfr. Parejo Alfonso, L. (2009b): “La Directiva Bolkenstein y la Ley paraguas: ¿Legitima el fin cualesquiera medios para la reconversión del Estado “autoritativo”?" Revista Española de Derecho Europeo n. 32; González García, J. (2009): "La transposición de la Directiva de servicios: aspectos normativos y organizativos en el Derecho español" Revista Española de Derecho Europeo n. 32.

37 El Comisario europeo Michel Barnier reconoce abiertamente que no es imprescindible la existencia un instrumento legislativo horizontal (paraguas) para la transposición de la Directiva. Incluso, más allá, y en contradicción con la posición de guardiana del respeto al Derecho comunitario que corresponde a la Comisión, señala que el retraso en la transposición de la Directiva no constituye el fin del mundo ("le délai de mise en oeuvre de la directive ne constitue pas la fin de l'histoire"). Comparecencia del Comisario ante el Parlamento Europeo el 27 de abril de 2010. Disponible en http://ec.europa.eu/commission_2010-2014/ barnier/headlines/speeches/2010/04/20100427_fr.htm. Acceso 22 mayo 2010. $202 \quad 38$ Sobre el reparto interno de competencias y la transposición de la Directiva, vide in toto, Muñoz 


\section{AFECTACIÓN AL RÉGIMEN ADMINISTRATIVO DE LA SEGURIDAD INDUSTRIAL EN ESPAÑA ${ }^{39}$}

La DSMI propone un enfoque transversal que afecta a multitud de normas y sectores. Consciente de ello, el Gobierno publicó, el 3 febrero de 2009, un documento con los resultados preliminares de la evaluación de la normativa a la Administración General del Estado ${ }^{40}$ Esta afectación por casos, comporta un diagnóstico preliminar de las normas de rango reglamentario (además, lógicamente de la Ley 21/1992, de 16 de julio, de Industria y sus homólogas de carácter autonómico) ${ }^{41}$.

Todos estos trabajos preliminares desembocan en la Ley 25/2009, de 22 de diciembre, de modificación de diversas leyes para su adaptación a la Ley sobre el libre acceso a las actividades de servicios y su ejercicio (Ley Ómnibus) ${ }^{42}$. Por medio de esta Ley se modifican hasta 47 leyes estatales. En lo que a este estudio interesa, destaca el artículo 13 por el se que introducen varias modificaciones a la Ley 21/1992, de 16 de julio, de Industria que analizamos según la sistemática del propio texto legal.

\subsection{Libertad de establecimiento y declaración responsable del interesado}

Se modifica el artículo 4 de la Ley de Industria en el sentido de reconocer la libertad de establecimiento para la instalación, ampliación y traslado de las actividades industriales. Sólo se requerirá, en determinados casos, una comunicación o una declaración responsable del interesado, mediante la que se manifieste, en su caso, el cumplimiento de los requisitos exigidos. La comunicación o declaración responsable habilita desde el día de su presentación para el desarrollo de la actividad de que se trate en todo el territorio español y con una duración indefinida.

Se trata de la traslación al concreto sector de las actividades industriales de la libertad general de establecimiento contemplada por la DSMI. En cuanto a los requisitos documentales, no se exime a las actividades del necesario proyecto técnico y de

\footnotetext{
cho Administrativo, n. ${ }^{2}$ 21. Para Parejo Alfonso, el proceso de transposición ha "orillado cualquier reflexión no ya sobre la adecuación al orden constitucional sustantivo, sino incluso sobre el respeto a los límites derivados del reparto territorial interno del poder público" y por ello "evidencia la poca sensibilidad para con la lógica de la construcción territorial del Estado” Parejo Alfonso, L. (2009a): “La desregulación de los servicios con motivo de la Directiva Bolkenstein: la interiorización, con paraguas y en ómnibus de su impacto en nuestro sistema" El Cronista del Estado Social y Democrático de Derecho n. ${ }^{\circ}$, p. 40.

39 El presente apartado se dedica única y exclusivamente a analizar la afectación que la Ley 25/2009 produce sobre la Ley de Industria y no a la descripción general del régimen jurídico de la seguridad industrial en España para lo que existe ya numerosa y calificada doctrina recogida en parte en la nota 8.

40 De la multitud de áreas afectadas, existen otras áreas que pueden ser de interés por el carácter conexo que presentan con la materia de seguridad industrial, especialmente las relativas a energía y a metrología. Vide el listado entero en www.meh.es (último acceso 29 abril 2010).

41 Cfr. Listado de normativa estatal con rango reglamentario susceptible de modificación. Aprobado por Acuerdo del Consejo de Ministros el 12 de junio de 2009. Disponible en www.meh.es (último acceso 29 abril 2010).

42 BOE n. 308 de 23 de diciembre de 2009.
} 
cuantas otras reglamentaciones sean exigibles. Lo que se modifica es el trámite administrativo. En otras palabras, quien quiera establecer una industria va a seguir necesitando igualmente un proyecto técnico redactado por un profesional que guardará en su poder y declarará a la Administración que lo tiene. No se desregula o liberaliza el establecimiento sino que se simplifica el trámite administrativo. En vez de deber iniciar un procedimiento administrativo que finalice con una autorización será suficiente con una autodeclaración responsable y con custodiar la documentación y facilitar el control por parte de la autoridad competente si esta lo estima oportuno.

Ciertamente, la posición de la Administración se ve profundamente alterada. En vez de situarse en un primer momento, como habilitador del funcionamiento de la actividad, queda en una situación de supervisión posterior. Ello necesitará sin lugar a dudas de un gran refuerzo de los servicios de inspección administrativa ${ }^{43}$. Como contrapartida, en caso de detectarse un incumplimiento de las condiciones que han sido declaradas, se decretará automáticamente el cese de la actividad. (Expediente informativo + 15 días + subsanación en su caso). Y, como correlato lógico, el inicio de actividades sin realizar la correspondiente autodeclaración o falseando sus datos constituye un supuesto sancionable [art. 31.2 de la Ley de Industria al que se añaden dos tipos sancionadores: k) y l)].

\subsection{Vigencia de los reglamentos de seguridad}

En conjunción con lo anterior, se mantiene que los Reglamentos de Seguridad (art. 12) podrán condicionar el funcionamiento de determinadas instalaciones y la utilización de determinados productos a que se acredite el cumplimiento de las normas reglamentarias, en los términos que las mismas establezcan.

La formulación del artículo 12, pues, supone un respaldo a las medidas técnicas que deban cumplir las instalaciones industriales. De nuevo, la Ley 25/2009 (y la 17/2009 de la que trae causa), son básicamente medidas normativas transversales que afectan la posición de la Administración pública y sus procedimientos pero que no liberalizan materialmente el fondo de la cuestión. Así, si una empresa debía reunir unas determinadas condiciones reglamentarias de seguridad de sus instalaciones, equipos o productos, seguirán las mismas obligaciones aunque el modo de acreditarlas será diverso. Otra cosa es que en el proceso de revisión del impacto de la reforma se deba cumplir con lo dispuesto en el art. 4.4. de la Ley de Industria reformada, es decir, que los requisitos de acceso a la actividad y su ejercicio en materia industrial serán propor-

43 Parejo Alfonso (2009a) incide críticamente en este aspecto al señalar que la transposición amplia de la DSMI si bien podría justificarse desde el punto de vista de su objetivo económico, no puede decirse lo mismo desde el punto de vista jurídico. Se afecta a la integridad del propio sistema administrativo, "teniendo en cuenta su incidencia en un Estado administrativo montado sobre la policía administrativa preventiva y básicamente inhábil (por carente de las estructuras, medios personales, procedimientos y técnicas) para el desarrollo inmediato de una policía administrativa de supervisión y control ex post", Parejo Alfonso, L. Op. cit. p. 39. 
cionados, no discriminatorios, trasparentes y objetivos, y estarán clara y directamente vinculados al interés general concreto que los justifique ${ }^{44}$. Pero ello no obsta que la transposición de la DSMI no afecta, per se, a la reglamentación técnica existente. Dicho en otras palabras, si un establecimiento musical debía cumplir determinados requisitos reglamentarios de insonorización, sigue estando igualmente sujeto a los mismos.

Sí resulta novedosa la dicción del apartado 5 que propone una especie de armonización estatal de los reglamentos de seguridad en clara contradicción con la jurisprudencia constitucional que ha reconocido reiteradamente la competencia ejecutiva en materia de industria a las Comunidades Autónomas ${ }^{45}$. Desde el punto de vista de la distribución competencial, la reforma resulta claramente centralizadora.

\subsection{Validez nacional de las comunicaciones o declaraciones}

Se modifica el apartado 3 del artículo 13, de manera que ahora, las comunicaciones o declaraciones responsables que se realicen en una determinada Comunidad Autónoma serán válidas, sin que puedan imponerse requisitos o condiciones adicionales, para el ejercicio de la actividad, en todo el territorio español.

Efectivamente, creemos que no era congruente con el principio de unidad de mercado que las autorizaciones concedidas por las Comunidades Autónomas en ejercicio de su competencia ejecutiva en materia de Industria no tuvieran validez en todo el Estado ${ }^{46}$. Finalmente la reforma recoge estos aspectos.

\subsection{Organismos de control}

La reforma en materia de seguridad industrial es sin duda de mayor calado en lo que los organismos de control, entidades colaboradoras de la Administración, se refiere (art. 15) ${ }^{47}$. Se produce la abolición definitiva del sistema concesional como título

44 Vide de nuevo, el Listado de normativa estatal con rango reglamentario susceptible de modificación. Aprobado por Acuerdo del Consejo de Ministros el 12 de junio de 2009, op. cit., nota 30.

45 vide por ejemplo SSTC 33/2005, de 17 de febrero y 332/2005, de 15 de diciembre, ambas recogidas en nuestro trabajo Padrós Reig, C. (2007): La competència autonòmica executiva sobre el règim administratiu de les activitats d'inspecció tècnica. Institut d'Estudis Autonòmics. Generalitat de Catalunya.

46 Padrós Reig, C. (2000): Actividad administrativa y entidades colaboradoras. Tecnos, Madrid; Padrós Reig, C. (2007): La competència executiva autonòmica sobre el règim de les entitats col.laboradores en la inspecció tècnica. Barcelona, Institut d’Estudis Autonòmics.

47 De nuevo, el objeto de este trabajo no es presentar el régimen legal de los organismos de control industrial, ambiental o de vehículos para lo que existen ya abundantes referencias bibliográficas. Fernández Farreres, G (1998). "La infraestructura organizativa para la calidad y la seguridad industrial y el fenómeno del ejercicio por particulares de funciones públicas de inspección y control” en Revista Aragonesa de Administración Pública n. 13; Macera, B.F. (2000): "La problemática de la asunción de la inspección administrativa por entidades privadas. Especial referencia al sistema de vigilancia ambiental de las actividades clasificadas" en EI Derecho Administrativo en el umbral del siglo XXI. Homenaje al profesor Dr. Ramón Martín 
habilitante para el ejercicio de estas actividades así como el levantamiento de la compartimentación autonómica de los mercados ${ }^{48}$. La autorización de los Organismos de Control corresponde a la Administración competente en materia de Industria del territorio donde los Organismos inicien su actividad o radiquen sus instalaciones. Las autorizaciones otorgadas a los Organismos de Control tendrán validez para todo el ámbito del Estado y duración indefinida. La condición de organismo de control podrá obtenerse con la acreditación de los requisitos técnicos por parte incluso de personas naturales siempre que cuenten con la imparcialidad y los medios suficientes para ejercer su cometido ${ }^{49}$.

Como reflexión general, cabe decir que la liberalización del régimen jurídico de los organismos de control no significa para nada su menosprecio. Todo lo contrario, las Administraciones públicas podrán realizar un recurso incluso más intenso a estos prestadores. Como indica la propia DSMI (considerando 48), “Las ventanillas únicas pueden estar constituidas no solo por autoridades administrativas sino también por cámaras de comercio o de oficios, colegios profesionales u organismos privados a los que los Estados miembros encomienden esta función. La finalidad de las ventanillas únicas es desempeñar un importante papel de ayuda al prestador, ya sea como autoridad directamente competente para expedir los documentos necesarios para acceder a una actividad de servicios, ya sea como intermediario entre el prestador y dichas autoridades directamente competentes".

De toda la filosofía de la reforma normativa, destaca, a título de ejemplo, la nueva redacción de los artículos 42 y 43 del Reglamento de Infraestructura para la Calidad y la Seguridad Industrial, que en aquello relativo a la acreditación de las entidades, ha sido objeto de modificación por el RD 338/2010 de 19 de marzo50.

Como se pone de relieve, la Ley 25/2009 produce una afectación importante en materia de seguridad industrial mediante la modificación expresa de la Ley de Indus-

\footnotetext{
Mateo. Tirant Lo Blanch, Valencia; Nogueira López, A. (2009): “Entidades colaboradoras con la Administración, libre prestación de servicios y régimen de control preventivo de las actividades" Revista Aranzadi de Derecho Ambiental n. 16; Ocharán de la Cámara, E. (1981): “Las entidades colaboradoras de la Administración en la CEE” Economía Industrial, vol. 207 n. ³; Ojeda Marín, A. (1982): “Entidades privadas colaboradoras de la Administración en el ámbito técnico”, en Homenaje a José Antonio García-Trevijano Fos. Colegio Universitario de Estudios Financieros-Instituto de Estudios de la Administración Local. Madrid; Padrós Reig, C. (2010): La Administración invisible. Panorama general y ejemplos prácticos de entidades colaboradoras de la Administración pública. Dykinson, Madrid.

Nuestro objetivo se centra aquí más modestamente en presentar los cambios que la Ley 25/2009 produce sobre su naturaleza y normativa reguladora.

48 Hecho, por otra parte, no absolutamente novedoso puesto que la jurisprudencia había ya limitado en carácter exclusivo y excluyente de los monopolios concesionales en materia de control ambiental. Vide el comentario a la STSJCat de 9 de noviembre de 2001 en Padrós Reig, C. (2010): La Administración Invisible. Dykinson, Madrid.
}

49 El Presidente del Consejo General de Colegios de Ingenieros Técnicos Industriales expresa su escepticismo sobre la posibilidad que profesionales a título individual puedan ejercer tareas de control. Cfr. Martínez García, V. (2009): “La seguridad industrial y la Ley Ómnibus”, Técnica Industrial, n. 283 , septiembre-octubre, p. 5 .

50 BOE n. 84 de 7 de abril de 2010. 
tria, pero también indirectamente mediante la modificación de la Ley 3/1985, de 18 de marzo, de Metrología; de la Ley 38/1999, de 5 de noviembre, de Ordenación de la Edificación; y de la Ley 2/1974 de 13 de febrero sobre Colegios Profesionales. Todo ello afecta al régimen de actuación de los organismos de control. Baste retener ahora que mientras que las actividades industriales se someten al régimen de libertad de establecimiento (no hay autorización administrativa previa), para la actuación de los organismos de control de la seguridad, se mantiene dicha autorización (a pesar de que no se explicite la necesariedad y proporcionalidad del régimen de autorización). Se pasa pues de una libertad de cada Comunidad Autónoma para elegir el título jurídico con el que habilitar a los organismos de control a un régimen de autorización simple con validez estatal y duración indefinida.

\section{LA NORMATIVA CATALANA DE SEGURIDAD INDUSTRIAL}

Cataluña ha sido una Comunidad tradicionalmente activa en la regulación de las condiciones de seguridad industrial y ambiental de las actividades económicas. La actividad industrial es una fuente indudable de riqueza y a la vez de generación de riesgos y por ello, compatibilizar ambos aspectos mediante un adecuado sistema de gestión de la seguridad resulta crucial. Igualmente delicada se presenta la participación de los mundos público y privado en el modelo de seguridad industrial o ambiental. Con ese objetivo el Parlamento de Cataluña aprobó la Ley 12/2008, de 16 de julio, de seguridad industrial ${ }^{51}$. Si algo resulta claro en la nueva Ley es la apelación a una gestión compartida público-privada de los múltiples operadores que interactúan en materia de seguridad. En un esfuerzo encomiable (aunque no exento de voluntarismo), la Ley 12/2008 regula en su artículo 5, la responsabilidad de los varios agentes:

a) Los titulares de las actividades, las instalaciones o los productos industriales son responsables de tener las autorizaciones, las licencias, las inscripciones o los registros que sean preceptivos; de que las actividades, las instalaciones o los productos industriales se usen y se mantengan adecuadamente de acuerdo con las condiciones de seguridad legalmente exigibles, y de que se hagan las inspecciones periódicas establecidas por la normativa vigente.

b) Los técnicos competentes autores del proyecto de la actividad, la instalación o el producto industrial, o de la modificación del proyecto, son los responsables de que este se adapte a las condiciones de seguridad legalmente exigibles.

c) Los técnicos competentes directores de la ejecución del proyecto de la obra o la instalación, o de la ejecución de la modificación del proyecto, los cuales

51 DOGC n. 5191 de 8 de agosto de 2008; BOE n. 204 de 23 de agosto de 2008. 
tienen que emitir el correspondiente certificado si es preceptivo, son los responsables de adaptar la obra o la instalación al proyecto y de adoptar las medidas y cumplir las condiciones de seguridad legalmente exigibles en la materialización del proyecto. Si prestan los servicios para una empresa, esta es subsidiariamente responsable.

d) Los profesionales y las empresas que intervienen en la instalación, el mantenimiento, la reparación y la operación de instalaciones y productos industriales son responsables de tener las autorizaciones que sean preceptivas y de cumplir las condiciones de seguridad industrial legalmente exigibles, las normas técnicas reconocidas, las buenas prácticas profesionales generalmente aceptadas y los requisitos y las obligaciones correspondientes a tales autorizaciones. Si se trata de profesionales, las empresas por las que prestan sus servicios son subsidiariamente responsables.

e) Las empresas de suministro de energía eléctrica, gases o líquidos combustibles y de cualquier producto o servicio cuyo consumo requiera instalaciones o productos sometidos a reglamentos técnicos de seguridad industrial son responsables de suministrar su producto o servicio únicamente si dichas instalaciones o dichos productos tienen las autorizaciones, las licencias, las inscripciones o los registros que sean preceptivos.

f) Los fabricantes o importadores de productos industriales son responsables de poner en el mercado únicamente productos seguros, de acuerdo con lo que establecen la legislación específica aplicable, las normas técnicas reconocidas y las buenas prácticas profesionales generalmente aceptadas.

g) Los talleres de reparación de vehículos automóviles y de sus equipos y componentes son responsables de tener las autorizaciones que sean preceptivas; de instalar y utilizar, en las reparaciones que realicen, únicamente piezas, elementos y conjuntos permitidos por la normativa aplicable, y de cumplir las obligaciones correspondientes a su autorización.

h) Los operadores de la inspección en materia de seguridad industrial son responsables de tener las autorizaciones que sean preceptivas, de desarrollar sus funciones de acuerdo con lo establecido por esta Ley y de seguir las instrucciones y los protocolos que establezca la Agencia Catalana de Seguridad Industrial.

i) El personal inspector de los operadores de la inspección en materia de seguridad industrial es responsable de realizar sus funciones de evaluación de conformidad, de acuerdo con los reglamentos técnicos de seguridad industrial aplicables y las instrucciones y los protocolos que establezca la Agencia Catalana de Seguridad, y de cumplir las obligaciones correspondientes a su autorización. Los operadores de la inspección para los cuales prestan servi208 cios son subsidiariamente responsables. 
j) El resto de entidades que realizan actividades de certificación, ensayo, inspección, evaluación de conformidad, evaluación de riesgos, auditoría o formación en materia de seguridad industrial son responsables de tener las autorizaciones que sean preceptivas, de desarrollar sus funciones de acuerdo con lo establecido por la normativa aplicable y de seguir las instrucciones y los protocolos que establezca la Agencia Catalana de Seguridad Industrial.

Queda claro, pues, que la seguridad industrial implica a multitud de actores o agentes, tanto pertenecientes al mundo público como al privado. A los efectos de definir el objeto de la Ley, el artículo primero de la Ley 12/2008, explicita lo que deba entenderse por seguridad industrial:

1. El objeto de la presente Ley es la regulación, dentro del ámbito de competencias de la Generalidad, del marco jurídico general de la seguridad industrial en el territorio de Cataluña, incluyendo la vigilancia del mercado en esta materia.

2. La seguridad industrial es un servicio público de interés general que tiene por objeto prevenir los riesgos industriales, limitarlos a un nivel socialmente aceptable y mitigar las consecuencias de los accidentes, si se producen, que puedan causar daños o perjuicios a las personas, los bienes o el medio ambiente como resultado de la actividad industrial, de la utilización, el funcionamiento y el mantenimiento de las instalaciones industriales o de la producción, el uso, el consumo, el almacenaje o el desecho de los productos industriales.

En primer lugar, pues, salta a la vista la contradicción misma en la que incurre el legislador catalán. De una parte define la seguridad industrial como un servicio público de interés general y de otra, da responsabilidad administrativa a la Generalitat para la vigilancia del mercado de prestación de servicios. Es cierto que no necesariamente la calificación de un sector como de servicio de interés general comporta el excluirlo de las normas del mercado. Así lo ha establecido numerosa jurisprudencia del TJCE. Sin embargo, choca la definición en el mismo cuerpo legal de la misión de servicio público y de la existencia de un mercado. Si recurrimos al Preámbulo de la norma, el carácter obligatorio de la prestación y la incapacidad de los usuarios para evaluar la calidad de los servicios prestados, indica la inexistencia o la inconveniencia de un mercado. Existirá, si acaso, una pluralidad de operadores de seguridad que -aun siendo privados- desarrollan todos ellos una actividad económica de interés general (incluso un servicio público impropio si se quiere). Como operadores privados de una función de interés general (pública), estarán sujetos a multitud de controles, planificación, zonificación, tarificación o cuanto sea menester. Pero la base de esa intervención no es la regulación de un mercado de servicios sino la ordenación del desarrollo de una potestad pública52.

52 En este sentido resulta certero el Dictamen del Consell de Treball, Econòmic i Social de Catalunya de fecha 3 de febrero de 2007 , donde a propósito de esta contradicción, se considera que: "EI CTESC considera que la expresión "vigilancia del mercado en esta materia" que se utiliza en el Preámbulo y en el articulado del Anteproyecto de Ley, pueden dar lugar a diferentes interpretaciones y, por ello, recomienda que se aclare este concepto". 
En segundo lugar, existe una patente desconexión entre el modelo autorizatorio de Cataluña y las propias previsiones de la DSMI. No está de más recordar que la Directiva se aprobó a finales de 2006 y justo en el momento en que el Parlamento autonómico desarrollaba los trabajos parlamentarios para la aprobación de la Ley catalana. Las previsiones de la Directiva no son directamente aplicables a los ciudadanos hasta agotado el plazo de transposición (31 de diciembre de 2009), pero sí vinculan a los Estados miembros ( $\mathrm{y}$ a sus Administraciones subestatales). Constituiría una vulneración de las obligaciones de Derecho comunitario aprobar normativas que contradigan o comprometan el efecto útil de Directivas europeas en fase de transposición ${ }^{53}$.

Lo cierto, es que desde el punto de vista del test de compatibilidad entre la Directiva y la Ley catalana, podría admitirse que el legislador catalán hiciera un uso más extensivo de la capacidad para regular servicios de autoridad o servicios públicos de interés general. La Directiva lo permite aunque seguramente se estuviera pensando en otros supuestos. Así, aunque infiel al espíritu de la DSMI que establece la libertad de acceso de los prestadores de servicios empresariales, la Ley catalana 12/2008 podría calificarse de acorde con el texto DSMI.

La complicada entremezcla de los mundos público y privado se pone igualmente de manifiesto en la creación y regulación de la Agencia Catalana de Seguridad Industrial a la que Ley dedica un considerable espacio. La Agencia es una entidad de derecho público de la Generalitat con personalidad jurídica propia y que actúa bajo las normas de derecho privado (excepto en aquello que implique ejercicio de potestades públicas, que no se definen en el texto legal). La Agencia se erige como la unidad administrativa sobre la que pivota en sistema de control de la seguridad industrial. Entre las funciones de la Agencia, destacan la ejecución general de la política de seguridad industrial; la autorización de los organismos privados; la vigilancia y control sobre los operadores y la responsabilidad de asegurar la prestación universal del servicio de inspección (sic) ${ }^{54}$.

El Dictamen 18/2007 del Consell de Treball, Econòmic i Social de Catalunya, aprobado en su sesión de 3 de diciembre de 2007 es fuertemente crítico con la creación de esta agencia. Así, se considera que "la creación de la Agencia no tiene ninguna justificación como necesidad de servicio y, en consecuencia, no se estima necesario crearla." O incluso de forma más preocupante, se pone de relieve la total indefinición de estos monstruos jurídicos: "es jurídicamente inadmisible que en determinados casos, sin especificar en cuales, la Agencia actúe como poder público, y por tanto, los actos dictados constituyan actos administrativos. El ciudadano debería conocer de antema-

53 El Dictamen del Consell Consultiu n. ${ }^{\circ} 272$ de 19 de mayo de 2006 no dedica siquiera un párrafo a la compatibilidad entre Ley catalana y DSMI puesto que el texto europeo no se hallaba todavía en vigor. Distinto es el caso del Dictamen 18/2007 de 3 de diciembre de 2007, en este caso del Consell de Treball, Econòmic i Social de Catalunya que se dicta en vigencia de la Directiva (casi un año después) y tampoco merece especial atención.

54 como veremos, la caracterización de la inspección industrial como servicio público chocaría en este caso con la legislación básica estatal contenida en la Ley 17/2009. 
no en que casos la Agencia se constituye como poder público para arbitrar las medidas legales que correspondan para la defensa de sus intereses" ${ }_{55}$.

Resulta cierto que la Directiva deja a salvo la definición de los servicios públicos para cada uno de los Estados miembros. Cada Estado miembro puede -en el marco de las restricciones que ha establecido la jurisprudencia del Tribunal- declarar una determinada actividad económica como servicio de interés general y sustraerla a las normas generales de competencia y libertad de acceso. La posición del legislador catalán es algo más compleja: por una parte declara que estamos ante un servicio público pero por otra considera que es necesario regular el mercado de la prestación. La Generalitat actuaría no en base a una competencia general de autoorganización de sus potestades administrativas sino como una especie de regulador sectorial (al estilo de las Comisiones Nacionales de la Energía o de las Telecomunicaciones) ${ }^{56}$. Dicho en otras palabras, el legislador puede legítimamente restringir el ámbito de aplicación objetivo de la DSMI si declara servicios públicos temas que no están expresamente recogidos en el texto de la norma europea. En ese caso, deberá superar los controles de la jurisprudencia del Tribunal en cuanto a la proporcionalidad e idoneidad de sustraer determinados ámbitos del giro económico a las reglas del mercado.

Sea como fuere, y hecha patente esta ambivalencia del legislador, Cataluña opta por un modelo más restrictivo desde el punto de vista DSMI que el Tribunal de Justicia puede tener ocasión de examinar en el futuro pero que prima facie se presume legal. La Directiva se aplica a aquellos servicios que son un mercado. Para los que no lo son -ya sea por naturaleza o por exclusión del legislador- los controles del Tribunal determinarán el carácter acorde o no con las libertades comunitarias de las restricciones a la libre competencia y la libre circulación. Pero el legislador autonómico tiene un espacio de potestad soberana para declarar la seguridad industrial como servicio público ${ }^{57}$.

A título de ejemplo de lo anterior, puede argumentarse que para el caso de las ITV, la Ley catalana queda invalidada por el pronunciamiento contenido en la sentencia STJCEE de 22 de octubre de 2009 (As. C-438/08 Comisión contra República Portuguesa), pero no por la DSMI en si misma. Una vez declarada la ilegalidad comunitaria de las autorizaciones en materia de organismos de control, resultará especialmente afectada la disposición del art. 12 de la Ley 12/2008 cuando establece que corresponde a la Agencia Catalana de Seguridad Industrial, otorgar las autorizaciones de los organismos de control y los titulares de las estaciones de inspección técnica de vehículos, así como, si procede, revocarlas o suspenderlas, de acuerdo con lo establecido por la presente Ley.

55 Irónicamente la Administración catalana puede haber caído en su propia trampa. Si se recurre a las formas privadas de prestación para escapar de las rigideces del Derecho administrativo, difícilmente podrá argumentarse después de que estamos ante un ejercicio de autoridad pública, para escapar en este caso de la imposición de las libertades comunitarias. O se es Administración pública o se es operador privado. Lo que no cabe es ser operador privado con los privilegios de la naturaleza pública (posibilidad de reserva del mercado).

56 sobre la distinción entre servicio-potestad y servicio público, vide De la Quadra Salcedo, T. (2005): “Estado y mercado en un mundo global”, Cuadernos de Derecho Público, n. 25.

57 No es así en cambio después de la aprobación de las Leyes 17/2009 y 25/2009. 
Tal autorización desaparecería pues con la aplicación combinada de la jurisprudencia del Tribunal y de las previsiones de la DSMI58. Y la misma suerte podrían correr (por analogía) las autorizaciones de otros organismos de control en la misma disposición (art. 12 Ley 12/2008):

e) Otorgar las autorizaciones de las demás entidades que realizan actividades de certificación, ensayo, inspección, evaluación, auditoría o formación en materia de seguridad industrial si es preceptivo, así como, si procede, revocarlas o suspenderlas. Controlar su actividad y aprobar las instrucciones y los protocolos de actuación correspondientes, de acuerdo con la normativa aplicable.

f) Otorgar las autorizaciones de las personas físicas o jurídicas que intervienen en la instalación, el mantenimiento, la reparación y la operación de instalaciones y de productos industriales si es preceptivo, así como, si procede, revocarlas o suspenderlas. Controlar su actividad y aprobar las instrucciones y los protocolos de actuación correspondientes, de acuerdo con la normativa aplicable.

\section{(...)}

k) Ejercer las competencias que corresponden a la Generalidad en materia de control metrológico, entre las cuales: otorgar, y, si procede, revocar o suspender las autorizaciones de los organismos que realizan actividades de control y verificación metrológica y controlar sus actuaciones de acuerdo con lo establecido por la normativa aplicable.

I) Ejercer las competencias que corresponden a la Generalidad en materia de contrastación de metales preciosos, entre las cuales: otorgar, y, si procede, revocar o suspender las autorizaciones de los laboratorios de contrastación y controlar sus actuaciones de acuerdo con lo establecido por la normativa aplicable.

Por el momento, y si nos situamos en el momento de la aprobación de la Ley 12/2008 (julio 2008), la opción del legislador catalán era legal aunque no anticipaba los cambios que se producirían en el futuro inmediato.

En otro orden de cosas, y siguiendo con el razonamiento de la Ley $12 / 2008$, si las actuaciones de los organismos de control conforman una parte de la potestad administrativa de inspección, resulta coherente que el personal inspector de los operado-

58 Concordando pues con la apreciación del profesor Tomás Ramón Fernández de que el potencial liberalizador no está tanto en la propia DSMI como en la jurisprudencia del Tribunal. Cfr. Fernández Rodrí212 guez, T.R. (2007): “Un nuevo Derecho Administrativo para el mercado interior europeo”, Revista Española 
res de la inspección en materia de seguridad industrial, deba tener la competencia profesional pertinente, así como mantenerla y actualizarla. Dicha competencia profesional supone la existencia, la idoneidad, la suficiencia, el mantenimiento y la actualización de las calificaciones, los conocimientos técnicos, las habilidades personales y la experiencia profesional para desarrollar las funciones y las tareas de inspección. Se trata, como ya hemos visto de una legitimación de la función administrativa por la competencia técnica. No se trata de funcionarios ni agentes de autoridad pero su especial calificación hace que sus apreciaciones deban gozar de especial consideración. Ciertamente puede adolecer de cierta extensión la equiparación automática de los certificados emitidos por el personal inspector de los operadores privados de la inspección en materia de seguridad industrial que efectúa la Ley (art. 25.3.) Según el precepto legal (que sin duda será objeto de discusión), tienen la misma validez jurídica los certificados de los organismos de control emitidos por técnicos cualificados que las actas de inspección propiamente hablando emitidas por personal inspector funcionario de la Agencia Catalana de Seguridad Industrial ${ }^{59}$.

Junto con el valor técnico de las actas, certificados o informes de organismos colaboradores en materia de seguridad industrial, destaca también la garantía firme e indubitada respecto a la independencia de la actuación de dichos organismos. Así, competencia técnica e independencia deben ser los dos elementos garantizadores de la objetividad de las actuaciones. Los operadores de la inspección en materia de seguridad industrial, su personal de dirección y su personal inspector deben ser independientes de las partes involucradas. El régimen de incompatibilidades debe desarrollarse por Decreto.

El debate existente acerca de la vinculación entre organismo colaborador y Administración pública titular de la competencia se zanja en el artículo 26 donde se establece sin vacilación que el régimen de prestación de los servicios de inspección es el de autorización administrativa. Los organismos colaboradores no son, pues, concesionarios administrativos de una función pública o cuasi-pública sino autorizados o acreditados para prestar los servicios que tengan encargados. De esta forma, la Ley se acerca a la configuración del control industrial como servicio económico ofertado a los titulares de empresas e instalaciones. El posterior desarrollo reglamentario de la Ley ha de indicar las características mínimas del sistema de prestación de los servicios de inspección, para garantizar que dichos servicios tienen una cobertura territorial adecuada, para asegurar su calidad y para establecer unas condiciones de competencia efectiva y leal entre los operadores.

Ello, dicho sea de pasada, comporta una nueva incongruencia del legislador. Si resulta que excluimos de las reglas de la libre prestación de servicios a las actividades de

59 De nuevo el CTESC ya pone de relieve esta cuestión en el Dictamen 18/2007 de 3 de diciembre: "el CTESC considera que el hecho que los certificados emitidos por los inspectores de los operadores de la inspección en materia de seguridad tengan la misma validez jurídica que los certificados emitidos por los inspectores de la Agencia Catalana de Seguridad Industrial, puede comportar, de facto una presunción de veracidad para los primeros, que en ningún caso se les puede atribuir". 
control industrial por formar parte integrante de un complejo entramado público-privado de garantía de la seguridad del ciudadano, no se entiende después que el título habilitante sea la autorización simple ni que se fomente la competencia entre operadores.

Llegados a este punto, conviene preguntarse acerca de la posibilidad en la Ley 12/2008 de que la misma Agencia de Seguridad Industrial restrinja el número de operadores. Dicho en otras palabras, la principal diferencia que existía entre el régimen concesional y el de autorización simple era la accesibilidad a la condición de operador-colaborador. Mientras que la concesión permitía restringir el número de operadores, la autorización no. La Ley aborda este crucial aspecto en su artículo 31, según el cual,

"El Gobierno, para asegurar una buena prestación del servicio con relación al parque de instalaciones existente y garantizar la objetividad y la calidad de la inspección, puede fijar, por decreto, el número máximo de organismos de control que actúan en Cataluña. En tal caso, debe establecerse un procedimiento de concurrencia pública y adjudicación por concurso entre los solicitantes."

La restricción al número de operadores puede justificarse en una situación de mercado competitivo libre para evitar la llamada "overcompetition" o lo que es lo mismo, evitar que la excesiva competencia entre operadores pueda mermar la calidad de los servicios o la rentabilidad y perdurabilidad de los mismos. Así, en el mercado del transporte por carretera, el antiguo contingente de tarjetas de transporte servía para proteger al sector de la excesiva concurrencia y de la tentación de ajustar los precios de los fletes mediante prácticas prohibidas (conducir más horas de las permitidas). En cambio, en el sector de los operadores colaboradores de la seguridad industrial, este peligro parecería conjurado ya al utilizarse el mecanismo de los precios comunicados. (art. 28.1). La disciplina de precios en los servicios de control cuenta pues con dos mecanismos de tope: el "price cap" o precio máximo fijado por la Administración y el precio comunicado mínimo. Es cierto, sin embargo que no existe un mecanismo de precio mínimo asegurado, lo que puede -a larga y según la estructura del sector- arrastrar los precios a la baja. Para intervenir sobre la estructura del sector y el peligro de concentración en pocos grupos empresariales, se dispone también de la prohibición de formar grupos (art. 30.1.b.) En cualquier caso, a pesar de la dicción imprecisa de la Ley, no se trata de una tarifa administrativa ni de un precio público. Finalmente, la Ley impone a los organismos de control, para poder actuar en el territorio de Cataluña, un desarrollo mínimo por comarcas y la asunción de un mínimo obligatorio de ámbitos de actuación.

La transición entre un mercado monopolista y un mercado libre como el que plantea la Ley $12 / 2008$, no queda tampoco exento de dificultades. En un primer momento, el gobierno propuso una prórroga del contrato concesional de las entidades colaboradoras. La prórroga fue objeto de dictamen por parte de la Comissió Jurídica Assessora quien calificó la modificación como desfavorable ${ }^{60}$.

60 Dictamen CJA 64/2003, de 6 de marzo de 2003. Efectivamente, por parte de la Generalitat se pretendía compensar a las concesionarias con un alargamiento del plazo para compensar unas supuestas 
Por tanto, y a modo de síntesis global, la opción restrictiva ejercitada por el legislador catalán en la Ley 12/2008 era conforme con las disposiciones de la Directiva de servicios, a pesar de sus incongruencias internas.

Sin embargo, la DSMI ha sido objeto de transposición en España mediante la aprobación de sendas leyes armonizadoras, o leyes marco. La Ley 17/2009, de 23 de noviembre, como ya hemos visto, establece que el principio general de libertad de entrada no se aplica a las actividades que supongan el ejercicio de la autoridad pública. Así, podría legítimamente pensarse que si los organismos controladores de la seguridad industrial en Cataluña ejercen autoridad pública (coadyuvan como agentes al buen desarrollo de la potestad pública de vigilancia de la seguridad industrial), quedarían fuera del ámbito objetivo de los servicios afectados por la Ley paraguas. De nuevo, al igual que hemos enunciado para la Directiva, la cuestión podría suscitar cierto debate (que se incrementa en parte con la aprobación un mes después de la Ley 25/2009). Efectivamente, junto con la ley paraguas (general), las Cortes Generales han aprobado la Ley 25/2009, de 22 de diciembre. En este segundo cuerpo normativo, queda claro que los organismos de control industrial no son considerados como sujetos que ostenten ejercicio de autoridad según la reforma del art. 15.1. Ley 21/1992 de 16 de julio, de Industria, cuyo literal especifica que:

"Los Organismos de Control son aquellas personas naturales o jurídicas, que teniendo capacidad de obrar, dispongan de los medios técnicos, materiales y humanos e imparcialidad necesarios para realizar su cometido y cumplan las disposiciones técnicas que se dicten con carácter estatal a fin de su reconocimiento en el ámbito de la Unión Europea.".

Las disposiciones de la Ley que afectan nuestro discurso se dictan al amparo de la competencia exclusiva del Estado para dictar las bases y coordinación de la planificación general de la actividad económica (art. 149.1.13) y por ello, la Ley catalana 12/2008, podría adolecer de inconstititucionalidad sobrevenida ${ }^{61}$. De hecho, la legislación estatal y la catalana se mueven en dos planos conceptuales totalmente distintos. De una parte, el legislador catalán concibe los servicios de control industrial como una función pública (aunque su ejercicio se confiere a particulares) ${ }^{62}$ y por ello rodea

modificaciones contractuales procedentes de la adopción de un nuevo modelo de seguridad industrial. En realidad, las modificaciones no serían tales sino el cumplimiento mismo del contrato inicial, con lo cual, las discutidas modificaciones por razón del cambio de modelo no serían compensables.

61 Recordemos que hemos anunciado que, sólo a los efectos de mantener una hipótesis de trabajo, consideramos que las Leyes 17/2009 y 25/2009 son constitucionales. De hecho, hay fundadas razones para pensar que ello no es así pero el legislador autonómico no puede legislar como si las leyes del Estado se presumieran inconstitucionales. Además, en el momento de escribir estas páginas no consta la presentación de recurso de inconstitucionalidad alguno contra dichas leyes.

62 Al respecto, vide: Bermejo Vera, J. (2002): "Privatización y el nuevo ejercicio de función pública por particulares” Revista Aragonesa de Administración Pública, n. ${ }^{20}$; C Canals Ametller, D. (2003): El ejercicio por particulares de funciones de autoridad. Control, inspección y certificación. Comares, Granada; SainzMoreno, F. (1983)"'Ejercicio privado de funciones públicas”, Revista de Administración pública, n. $100-102$. Desde una perspectiva tangencialmente concurrente a este estudio, cfr. igualmente Cassese, S. "La partecipazione dei privati alle decisioni pubbliche - Saggio di Diritto comparato" disponible en http://www.irpa. eu/public/File/Seminari\%20DAC/Lezione\%2ointroduttiva\%2oprof.\%20Sabino\%20Cassese.pdf 
toda la autorización de los mismos de una serie de controles nada desdeñables. En cambio, la legislación estatal acoge con la fe del converso la versión más liberalizadora de la DSMI y podemos decir que sustrae a los organismos de control claramente del ámbito administrativo para situarlos en el ámbito de los servicios económicos a las empresas. Lo que a nuestro parecer queda bastante claro es que la definición de la Ley catalana 12/2008 de los organismos de control como comprendidos dentro de un "servicio público de interés general" debe ser objeto de revisión (no por imposición de la misma DSMI sino por el carácter básico de la legislación estatal de transposición de la DSMI).

En definitiva, la Ley catalana, después de tambalearse con la aprobación de la DSMI ha sido definitivamente tumbada por el legislador estatal. ¿Significa ello que los organismos de control no pueden ser objeto siquiera de autorización simple y reglada? Ni la Ley 25/2009 va tan lejos puesto que admite que la autorización de los organismos de control corresponde a la Administración competente en materia de industria del territorio donde los organismos inicien su actividad o radiquen sus instalaciones (art. 15.3 de la Ley de Industria en su nuevo redactado). Se mantiene, pues, la potestad autorizatoria de la Administración catalana para los organismos de control en la seguridad industrial. Pero profundizando más en la cuestión legal cabría formularse la siguiente paradoja: si la Ley estatal y la DSMI consideran que no son objeto de autorización las actividades económicas excepto que haya una razón imperiosa de interés general que justifique la intervención administrativa ex ante y los organismos de control no son ejercicio de autoridad, ¿cuál es entonces el título que legitima la autorización autonómica? ¿No debería tratarse de actividades simplemente comunicadas? A nuestro modo de ver, se trataría de la propia disposición modificada del art. 13.3. de la Ley 21/1992, de 16 de julio, de Industria, en cuanto dispone que "los Reglamentos de Seguridad podrán condicionar el funcionamiento de determinadas instalaciones y la utilización de determinados productos a que se acredite el cumplimiento de las normas reglamentarias, en los términos que las mismas establezcan". Si las normas reglamentarias de seguridad establecen la autorización de los organismos de control, se fundamentaría así la autorización administrativa ${ }^{63}$. No es por ello aplicable a los organismos de control de la seguridad industrial la libertad general del art. 4 de la Ley de Industria ni la del art. 5 de la Ley 17/2009.

A pesar de ello, la reglamentación sectorial que prevé la Ley catalana ${ }^{64}$ y la autorización del Estado en nada se parecen. Las principales dificultades surgen en varios aspectos:

63 Vide al respecto el RD 338/2010, de 19 de marzo, por el que se modifica el Reglamento de la Infraestructura para la calidad y la seguridad industrial (RD 2200/1995, de 28 de diciembre). En su nueva redacción el art. 42.1. del RICSI establece que "los Organismos de control, para poder ser autorizados a ejercer sus actividades ...". Luego se prevé una autorización administrativa como título de ejercicio de esta actividad.

64 Máximo exponente se presenta en el caso del Decret 45/2010 de 30 de març, por el que se 216 aprueba el Plan Territorial Sectorial de nuevas estaciones de ITV de Cataluña para el período 2010 - 
— la posibilidad de autorización de personas físicas

- el carácter indefinido de la autorización

- el carácter reglado de la concesión de la autorización

- la zonificación y la exigencia de un territorio mínimo de actuación

- la validez estatal de las autorizaciones

- la transición del modelo antiguo al nuevo.

Efectivamente, la Ley catalana ni siquiera recoge la posibilidad de ejercicio de funciones de control por profesionales autónomos. En cuanto al carácter indefinido de la autorización, esta es la regla general. Sólo se excepciona y permite la limitación temporal cuando se trate de autorizaciones que estén limitadas en número. En otras palabras, si no hay límite en las autorizaciones y se conceden tantas cuantas se solicitan, éstas deberán ser indefinidas. Si por las estrictas razones que prevé la Ley, se contingenta el número de autorizaciones, el título resultante de la adjudicación por concurso será limitado en el tiempo para evitar que un mismo autorizado se perpetúe en el puesto ${ }^{65}$. En cuanto al carácter reglado de la autorización, la Ley 17/2009, prevé que las autorizaciones solo podrán limitarse en función de la concurrencia de dos justificaciones: "la escasez de los recursos naturales" o "inequívocos impedimentos técnicos" (art. 8.1.). Ninguna de ellas parece concurrir en el caso de los organismos de control de la seguridad industrial. Finalmente, puede ser objeto de cuestionamiento el modo de transición del modelo concesional al libre. Efectivamente, según dispone el art. 8.2. apartado b) de la Ley 17/2009, una vez extinguida la autorización (la concesión en nuestro caso), no dará lugar a un procedimiento de renovación automática, y muy importante, no conllevará ningún tipo de ventaja para el prestador cesante ${ }^{66}$.

También, si se analiza la disposición del art. 11 de la Ley 17/2009, resulta que algunos instrumentos reguladores que son tradicionales en el modo de operar el sector en Cataluña, quedan calificados como "requisitos de aplicación excepcional sujetos a evaluación previa"67:

65 El Reglamento catalán de desarrollo de la LSI prevé que las autorizaciones obtenidas por concurso para ejercer las funciones de ITV tengan una duración de 30 años, lo que no es precisamente un período corto de tiempo. Véase al respecto las observaciones esenciales que manifiesta el Dictamen 20/2010 de la Comissió Jurídica Assessora de la Generalitat de Catalunya, de fecha 21 de enero. El ponente, el profesor Joaquim Ferret i Jacas considera este tema como una "observación de carácter esencial obstativa de la legalidad del proyecto" sometido a Dictamen. A pesar de ello, el Gobierno no rectificó este punto.

66 El Dictamen de la Comissió Jurídica Assessora 20/2010 habla incluso de una falsa reversión de los bienes de los antiguos concessionarios que pasan a manos de la Administración pero siguen siendo utilizados por los mismos, pervirtiendo el régimen legal de los bienes públicos del Texto refundido de Ley catalana de Patrimonio (DL 1/2002 de 24 de diciembre).

67 Muy parecidos sino iguales a los contendidos en el Cuadro 3, anteriormente presentado. 
- Restricciones cuantitativas o territoriales y, concretamente, límites fijados en función de la población o de una distancia mínima entre prestadores. Los fines económicos, como el de garantizar la viabilidad económica de determinados prestadores, no podrán invocarse como justificación de restricciones cuantitativas o territoriales.

- Requisitos que obliguen al prestador a constituirse adoptando una determinada forma jurídica; así como la obligación de constituirse como entidad sin ánimo de lucro.

- Requisitos relativos a la participación en el capital de una sociedad, en concreto la obligación de disponer de un capital mínimo para determinadas actividades o tener una cualificación específica para poseer el capital social o gestionar determinadas sociedades.

- Requisitos distintos de los exigidos para el acceso a las profesiones reguladas, contemplados en la Directiva 2005/36/CE del Parlamento Europeo y del Consejo, de 7 de septiembre de 2005, relativa al reconocimiento de cualificaciones profesionales, que reserven el acceso a una actividad de servicios a una serie de prestadores concretos debido a la índole específica de la actividad.

— La prohibición de disponer de varios establecimientos en el territorio español.

- Requisitos relativos a la composición de la plantilla, tales como tener un número determinado de empleados; ya sea en el total de la plantilla o en categorías concretas, o a la obligación de contratar con una procedencia o modalidad determinada.

- Restricciones a la libertad de precios, tales como tarifas mínimas o máximas, o limitaciones a los descuentos ${ }^{68}$.

- La obligación del prestador de realizar, junto con su servicio, otros servicios específicos o de ofrecer una determinada gama o surtido de productos.

Para todo este conjunto de restricciones o condiciones de ejercicio de la actividad, no existe una prohibición directa y automática sino que deberá justificarse su idoneidad por una razón imperiosa de interés general. Por ejemplo, si atendemos a la zonificación (comprendida en la lista en el primer apartado), habrá que justificar porque si la finalidad es garantizar un mayor acceso a la población de las estaciones de

68 Sobre las tarifas mínimas y máximas, vide el art. 51 de Decreto catalán 30/2010 que aprueba el Reglamento de Seguridad Industrial. No sólo se establece el mecanismo del "price-cap" sino que se impide la competencia en precios mediante una comparación con los resultados de otros operadores. Así se entiende pues que "las tarifas comunicadas por los operadores de la inspección en materia de seguridad in218 dustrial a la Agencia Catalana de Seguridad Industrial, no tienen que ser inferiores a los costes mínimos 
ITV, se puede imponer la distancia mínima. Con ello no queremos decir que no pueda existir dicha justificación. Probablemente puede argumentarse que de no imponer la zonificación obligatoria, los operadores tenderían a concentrarse territorialmente en las zonas más rentables desatendiendo las que lo son menos. Pero, ello habrá de probarse y justificarse convenientemente ${ }^{69}$.

En definitiva, si analizamos la afectación concreta a la Ley catalana 12/2008 que este nuevo paradigma legal produce, resulta que debe cuestionase la legalidad de los siguientes preceptos:

- artículo 30. Requisitos de los organismos de control;

- artículo 31. Régimen de autorización de los organismos de control (Número máximo de organismos de control que actúan en Cataluña);

- artículo 32. Autorización de los organismos de control (exigencia de autorización para poder actuar en Cataluña).

Y lo mismo puede decirse respecto del régimen de autorización previsto para las ITV en clara contradicción con el pronunciamiento TJUE de 22 de octubre de 2009 (Caso C-438/08):

- artículo 36. Requisitos de los titulares de las estaciones de inspección técnica de vehículos (adecuación al plan territorial de estaciones de inspección técnica de vehículos que, de acuerdo con el artículo 37.2. puede establecer el Gobierno) ${ }^{70}$;

- artículo 37. Régimen de autorización de los titulares de las estaciones de inspección técnica de vehículos (cuota máxima de mercado y distancias mínimas).

\section{ALGUNAS APORTACIONES RECIENTES}

Como colofón final a todo nuestro discurso, conviene analizar también la reciente aparición de algunos nuevos elementos normativos. En primer lugar, el Decreto catalán 30/2010 de 2 de marzo, por el que se aprueba el Reglamento de Seguridad Industrial (en desarrollo de la Ley 12/2008). De modo preliminar, cabe decir que la posición

69 La Autoridad Catalana de la Competencia, en su Informe 7/2010 de 31 de mayo de 2010, analiza de manera muy extensa e interesante cual es la justificación de todas estas retricciones y su impacto económico, concluyendo la inadecuación del establecimiento de numerus clausus, de la planificación por zonas o del régimen de continuidad de los antiguos operadores.

70 El Consell de Treball, Econòmic i Social de Catalunya, ha dictaminado el proyecto de decreto de por el que se establece el Plan Territorial en materia de estaciones de inspección técnica de vehículos en fecha 4 de enero de 2010, y aparte de los comentarios técnicos al articulado, no aprecia ninguna tacha de ilegalidad en aplicación de la DSMI. 
del Gobierno autonómico en la elaboración de esta norma queda altamente comprometida. Por una parte, están ya en vigor las Leyes 17/2009 y 25/2009 que pueden producir la ilegalidad sobrevenida de aspectos nada secundarios de la Ley 12/2008. Por otra parte, la misma ley catalana 12/2008 hace numerosas remisiones al desarrollo reglamentario que debe respetar el texto aprobado por el Parlament de Cataluña sin incurrir en un texto reglamentario carente de apoyatura legal ${ }^{71}$. Así pues, la inoportunidad del momento de aprobación del Reglamento es mayúscula.

A modo de valoración general, podemos decir que el Decret 30/2010 de 2 de marzo y el Reglamento que éste contiene desoyen completamente la legislación del Estado. No puede argumentarse ahora que el espacio normativo catalán fue ejercido legítimamente en desarrollo de la DSMI y que la ilegalidad de la Ley 12/2008 es sobrevenida. Se trata en cualquier caso del respeto al principio de jerarquía normativa, siendo inadmisible que los gobiernos autonómicos aprueben disposiciones de carácter general manifiestamente contrarias a la legislación del Estado. Si se argumenta que la legislación estatal puede ser inconstitucional por invadir las competencias catalanas, ello debería traducirse en la presentación del correspondiente conflicto de competencias. Además de ello, el Reglamento se aprueba el 2 de marzo de 2010, cuatro meses después de la publicación de la STJCEE de 22 de octubre de 2009 (As. C-438/08 Comisión contra República Portuguesa) que declara contrario al Derecho comunitario las restricciones de entrada en el sector de las ITV. A todo ello parece inmune la norma catalana.

Sea como fuere, no es difícil adivinar que el Reglamento de desarrollo de la Ley catalana de Seguridad Industrial presentará igualmente problemas de legalidad con el marco estatal, al igual que la Ley de la que trae causa ${ }^{72}$. El complejo y largo texto reglamentario (133 artículos) aborda separadamente distintos subsectores de la seguridad industrial de acuerdo con el siguiente esquema:

- organismos de control industrial (arts. 57-69)

- estaciones ITV (arts. 76-82)

— entidades de evaluación de conformidad de productos industriales (arts. 63-95)

— entidades de evaluación de riesgos industriales (arts. 96-105).

71 Este fenómeno puede apreciarse, por ejemplo, en la disposición del art. 115 RSI cuando permite la existencia de personas naturales como empresas de control industrial (inexistente en la Ley) o en el hecho mismo de introducir el principio de "libertad de instalación" (art. 7) inexistente en el texto legal.

72 Véase la concepción general que se traslada de la Ley al Reglamento en el art. 2 relativo al concepto de "servicio público de interés general”. A pesar de ello, el Reglamento recoge también el principio de "libertad de instalación" (art. 7) para aquellas actividades industriales que no estén sujetas a reglamentación específica y que no tiene parangón en la Ley 12/2008. Igualmente, se traslada de la Ley al Reglamento el principio de autorización administrativa previa que deben obtener los organismos de control "para

220 actuar en el territorio de Cataluña" (arts. 12 y ss). 
A estos operadores se les aplica una reglamentación específica, de manera que podemos obtener el siguiente cuadro resumen:

\section{CUADRO 6}

Resumen de las principales condiciones de autorización del Decreto 30/2010

\begin{tabular}{|l|l|l|l|l|l|l|}
\hline Tipo entidad & $\begin{array}{c}\text { Autorización } \\
\text { administrativa }\end{array}$ & $\begin{array}{c}\text { Limitación } \\
\text { número }\end{array}$ & $\begin{array}{c}\text { Prestación } \\
\text { mínima }\end{array}$ & Zonificación & $\begin{array}{l}\text { Personal } \\
\text { mínimo }\end{array}$ & $\begin{array}{l}\text { Requisitos } \\
\text { económicos }\end{array}$ \\
\hline OCI & sí & 6 & sí & Comarcas & sí & 10 mill. $€$ \\
\hline ITV & sí & $\begin{array}{l}50 \% \\
\text { cuota } \\
\text { mercado }\end{array}$ & & $\begin{array}{l}\text { Plan } \\
\text { territorial y } \\
\text { distancias } \\
\text { mínimas }\end{array}$ & sí & 10 mill. $€$ \\
\hline $\begin{array}{l}\text { Conformidad } \\
\text { de productos }\end{array}$ & $\begin{array}{l}\text { Sí y además } \\
\text { acreditación }\end{array}$ & no & Productividad & no & no & $\begin{array}{l}\text { Forma } \\
\text { societaria }\end{array}$ \\
\hline $\begin{array}{l}\text { Evaluación de } \\
\text { riesgos }\end{array}$ & Sí & no & no & no & no & $\begin{array}{l}\text { Forma } \\
\text { societaria }\end{array}$ \\
\hline
\end{tabular}

Interesa especialmente destacar como la mayoría (sino la totalidad) de estos requisitos incumplen la Ley estatal y la jurisprudencia del TJCE. Interesa especialmente mencionar dos disposiciones específicas: el artículo 60 cuando establece un despliegue territorial mínimo para los organismos de control de la seguridad industrial y el artículo 65 cuando establece el número máximo de organismos de control industrial sin que se aporte ninguna justificación para ello.

Y si trasladamos el análisis de los organismos de control a las entidades que realizan la inspección técnica de vehículos, se pueden detectar gravísimos problemas de encuadre legal, al menos en tres disposiciones: artículo 73 (Adecuación al Plan territorial y aseguramiento de la continuidad); artículo 74 (Cuota máxima de mercado) y artículo 75 (Distancias mínimas de compatibilidad) (sic).

La Comissió Jurídica Assessora, máximo órgano de la Administración Consultiva de la Generalitat de Catalunya tuvo ocasión de pronunciarse sobre el proyecto de Decreto que analizamos. En su Dictamen 20/2010 de 21 de enero, se argumenta a favor de una total deferencia a la Administración en la determinación y justificación de las razones imperiosas de interés general que justifiquen la intervención administrativa y su necesidad y proporcionalidad.

Además de lo anterior, el máximo órgano de la Administración consultiva catalana advierte en el Dictamen sobre el proyecto de Reglamento ${ }^{73}$, que la necesidad de autorización para las empresas de instalación, mantenimiento y reparación de insta-

73 Dictamen 20/2010 de la Comissió Jurídica Assessora de la Generalitat de Catalunya, de fecha 21 de enero de 2010. 
laciones y productos industriales (Título VII) y para los talleres de reparación de vehículos (Título VIII) no está motivada y por ello incumple la normativa europea y estatal.

Muy destacable resulta la regulación contenida en la Ley catalana 26/2010 de 3 de agosto, de régimen jurídico y de procedimiento de las Administraciones públicas de Cataluña. En efecto, la ley procedimental general regula en sus artículos 91 y ss. el régimen jurídico de las entidades colaboradoras (lo que incluye los organismos de control industrial). Con ello se está implícitamente admitiendo que la regulación de este tipo de entidades cae dentro del ámbito competencial del art. 149.1.18 (régimen jurídico de las administraciones públicas) y no simplemente en la ejecución de la materia "Industria". Ello puede tener importantes consecuencias en la discusión sobre la corrección competencial de la Ley 25/2009. En suma, la norma catalana configura las Entidades colaboradoras (lo serían las estaciones de ITV y los Organismos de Control Industrial, además de los de control ambiental y otros análogos), como "entidades técnicas especializadas, públicas o privadas, con personalidad jurídica propia, que han de disponer de los medios materiales y personales y también cumplir los requisitos de solvencia técnica y financiera establecidos por reglamento"74. No hay pues en la dicción legal ninguna característica que permita entender que se trata de entidades privadas que ejercen funciones de autoridad, y por ello quedan excluidas del régimen de libertad de establecimiento.

Sin embargo, se necesita de una habilitación (constitutiva) según el art. 92 de la norma catalana por la cual se declara la aptitud y capacidad de una entidad colaboradora para ejercer las funciones de inspección y control. Y más esclarecedor si cabe es el art. 95.3. del mismo cuerpo legal que determina que:

"Las actas, informes y las certificaciones emitidos por el personal técnico habilitado de las entidades colaboradoras en el ejercicio de las funciones de inspección y control tienen la misma validez jurídica que los emitidos por el personal de la Administración encargado de estas funciones."

Estamos pues ante el ejercicio privado de funciones públicas y ante la clara confrontación de dos principios jurídicos: si se es un sujeto privado, las actividades deben sujetarse a un régimen de libertad de establecimiento y prestación; si se es un sujeto público, se ejerce autoridad y por ello se excluye la aplicación de la DSMI. Los dos mundos pues confluyen en la regulación catalana.

Finalmente, el Decreto Legislativo catalán 3/2010, de 5 de octubre, regula la adecuación de normas con rango de Ley emanadas del Parlamento de Catalunya a la Directiva 2006/123/CE. De entre la docena de disposiciones afectadas, no existe ninguna relativa a la seguridad industrial. A título simplemente de anécdota, las contradicciones que hemos detectado para nuestro objeto de estudio se reproducen igualmente en el tema del visado colegial profesional. Así, la dicción del art. 70.d. de la Ley catala-

74 art. 91.2. de la Ley catalana 26/2010 de 3 de agosto. 
na 7/2006, de 31 de mayo mantiene que corresponde a los colegios visar los proyectos y trabajos de las personas colegiadas. Sin embargo, esta potestad de visar se ejercerá "en los términos y los efectos que determine la normativa correspondiente". Si la normativa correspondiente es el Real Decreto 1000/2010, de 5 de agosto, sobre el visado colegial obligatorio, la competencia del art. 70 queda prácticamente vacía. Si no es así, surgirá otra disonancia entre Estado-Comunidad en esta materia.

\section{CONCLUSIONES}

La DSMI, incluso en su versión final más moderada después de la intervención del Parlamento europeo, supone una radical transformación del papel de la Administración en materia de autorización de actividades económicas. En palabras del profesor Muñoz Machado, "el cambio de paradigma es de enorme envergadura, ya que obliga a las Administraciones públicas preparadas sobretodo para el control preventivo de la actividad económica de las empresas y sujetos privados, a orientar la preservación de los intereses públicos mediante un sistema de control a posterior"75.

Efectivamente, la DSMI constituye una norma de carácter transversal que afecta especialmente a la posición de la Administración dentro del proceso de intervención administrativa. La cuestión que hemos analizado hasta ahora es la autorización de los organismos de control de la seguridad industrial, que se mantiene pero se reformula su carácter (medida liberalizadora, en parte atribuible no a la DSMI sino a la propia jurisprudencia TJCE).

Además de ello, la afectación de la Administración es sumamente profunda en lo que al proceso autorizador de actividades refiere. Hasta ahora, la Administración se situaba en una posición de guardiana de acceso a las actividades, mediante un procedimiento autorizatorio previo. A partir de la DSMI, la Administración pierde esa potestad en la mayoría de los casos y queda relegada a un supervisor del sistema. Se trata a juicio de la doctrina de una "radical reconversión del sistema administrativo de control de las actividades de servicios"76. El paralelismo con la Administración tributaria es palmario. Los impuestos se autoliquidan por parte de los sujetos obligados. La Administración no tiene ninguna intervención en el procedimiento más que para detectar y perseguir fraudes o errores. La intervención administrativa ex post cumple perfectamente las finalidades que se le encargan, a pesar de no controlar inicialmente la liquidación.

Lo mismo puede decirse del cometido de la Administración que diseña la DSMI. De acuerdo con este sistema, los titulares de la actividad no deberán solicitar a la

75 Muñoz Machado, S. (2009): “Ilusiones y conflictos derivados de la Directiva de Servicios”, Revista General de Derecho Administrativo, n. ${ }^{\circ}$ 21, p. 3.

76 Parejo Alfonso, L. (2009): “La desregulación de los servicios con motivo de la Directiva Bolkenstein: la interiorización, con paraguas y en ómnibus de su impacto en nuestro sistema” El Cronista del Estado Social y Democrático de Derecho, n. ${ }^{\circ}$ 6, p. 34. 
Administración un permiso o licencia para desarrollar su empresa. Simplemente autodeclararán que cumplen los requisitos legales y será la Administración la que deberá controlar a posteriori si ello es verdad o no. Este cambio trascendental va a suponer necesariamente la activación de un sistema de información y control inexistente en la actualidad. También de un cuerpo de vigilancia de las actividades del que no se dispone en la actualidad. Sin duda, la DSMI a quien más afecta es a la Administración. A título de ejemplo, deberán de aprobarse planes de inspección sectorial para realizar muestreos del grado de cumplimiento de las autodeclaraciones (exactamente igual cómo la AEAT aprueba sus planes de inspección y control).

Ello puede comportar ciertos riesgos como detalla la propia explicación de la norma europea: "esto significa que la autorización solo es admisible en aquellos casos en que no resultaría eficaz hacer un control a posteriori, habida cuenta de la imposibilidad de comprobar a posteriori los defectos de los servicios en cuestión y habida cuenta de los riesgos y peligros que se derivarían de la inexistencia de un control a prior?"77.

Pero al tratarse de una norma transversal, afecta no sólo a la Administración del Estado sino a las Comunidades Autónomas que, por consolidada jurisprudencia constitucional tienen reconocida la competencia sobre la ejecución de la legislación en materia de Industria. El Estado español optó por una transposición "de máximos" de la Directiva, aprobando las Leyes 17/2009 y 25/2009. En el supuesto que estas dos leyes sean constitucionales, presentan un carácter claramente centralizador pues armonizan para el conjunto de las Administraciones los requisitos de autorización de las entidades de control. Ello supondría la ilegalidad de ciertas normas autonómicas como por ejemplo la catalana aquí analizada.

Es cierto que el proceso de transposición de la DSMI puede tener dos lecturas: desde el punto de vista de la estricta jerarquía normativa, sin más adornos, la Ley catalana 12/2008 y el Decret 30/2010, de 2 de marzo que aprueba su Reglamento son contrarios a la normativa estatal y europea. La actividad del legislador tendría la disculpa de haberse realizado con anterioridad a las leyes estatales y por tanto sería una incompatibilidad sobrevenida fruto sólo del patológico aislamiento de los varios procesos de creación normativa en el Estado de las autonomías. La actividad de la Administración (aprobación del Decreto 30/2010) sin embargo, no puede gozar de esa disculpa.

A pesar de ello, se podría argumentar la ilegalidad de la propia Directiva en tanto que obliga a los Estados no ya a armonizar sus ordenamientos administrativos para permitir la libre circulación de servicios sino a transformar radicalmente las tradiciones administrativas de cada país. En este sentido, la Directiva podría exceder de la competencia comunitaria ${ }^{78}$. Aun considerando como hipótesis la legalidad de la Directiva, la transposición hecha en España podría ser claramente inconstitucional por

77 Considerando 54 de la Directiva 2006/123/CE.

78 De la Quadra-Salcedo Janini, T. (2007): “¿Quo Vadis Bolkenstein? ¿Armonización o mera desregulación de la prestación de servicios”, Revista Española de Derecho Europeo, n.․ 22. 
vulnerar las competencias de las Comunidades Autónomas. En este sentido pues, el legislador catalán (y la Generalitat) mantendrían el modelo autorizatorio altamente restrictivo como forma de cuestionamiento del marco normativo superior. En línea de oportunidad más que de legalidad, la aprobación del Reglamento de Seguridad Industrial en Cataluña resulta como poco temeraria o manifiestamente rebelde. Si al final resultara que las leyes del Estado exceden de su cometido, la normativa catalana mantendría un modelo administrativo propio que sería igualmente contrario al Derecho europeo (con muchas dificultades compatible con la Directiva pero en ningún caso con la jurisprudencia del Tribunal).

Esta incompatibilidad con el Derecho europeo que hasta ahora era gratuita para las Comunidades -en el sentido de no ser directamente responsables de las sentencias condenatorias por incumplimiento del Derecho comunitario que podría sufrir el Estado como consecuencia de la actividad normativa de las Comunidades- ha sido objeto de transformación por la inclusión en la Disposición Final 4. ${ }^{a}$ de la Ley 17/2009 de un mecanismo de compensación con las transferencias que deban recibir las Comunidades. Así pues, desoír el ordenamiento comunitario de manera consciente puede tener consecuencias para la Administración catalana.

Finalmente, la aprobación por parte del Parlamento de Catalunya de la Ley 26/2010 de 3 de agosto de régimen jurídico y de procedimiento de las administraciones públicas en Catalunya, admite que las entidades colaboradoras de la administración (los organismos de control y las estaciones de ITV lo son), pueden conceptuarse como administraciones públicas y que sus manifestaciones con trascendencia externa (actas e informes), son iguales a las de la verdadera inspección administrativa. Ello supone dar la razón competencial al Estado en la utilización del título constitucional del art. 149.1.18 para fundamentar el carácter básico de la regulación del Estado. Por el contrario, admitir que ejercen funciones de autoridad les situaría dentro del ámbito de servicios excluidos de la DSMI (pendientes de superar el riguroso escrutinio del TJUE sobre la cuestión).

\section{BIBLIOGRAFÍA}

Albertí Rovira, E. (2006): “El desarrollo y ejecución por las Comunidades Autónomas de la normativa comunitaria en materias de competencia compartida con el Estado" en la obra colectiva Estatuto y Unión Europea. Institut d’Estudis Autonòmics. Barcelona.

Arana García, E. (1999): “Naturaleza Jurídica de la actividad de Inspección Técnica de Vehículos" Revista Vasca de Administración Pública, n. 54.

Bermejo Vera, J. (2002): "Privatización y el nuevo ejercicio de función pública por particulares" Revista Aragonesa de Administración Pública, n. 20.

Cabellos Espiérrez, M.A. (2001): Distribución de competencias, derechos de los ciudadanos e incidencia del derecho comunitario. Centro de Estudios Políticos y Constitucionales, Madrid. 
Canals Ametller, D. (2003): El ejercicio por particulares de funciones de autoridad. Control, inspección y certificación. Comares, Granada.

Carrillo Donaire, J.A. (2000): El derecho de la seguridad y de la calidad industrial. Marcial Pons, Madrid.

Fernández Ramos, S. (2002): La actividad administrativa de inspección. El régimen juridico general de la función inspectora. Comares, Granada.

De la Quadra Salcedo, T. (2005): “Estado y mercado en un mundo global” Cuadernos de Derecho Público, n. 25.

De la Quadra Salcedo, T. (Dir.) (2009): El mercado interior de servicios en la Unión Europea. Estudios sobre la Directiva 123/2006/CE relativa a los servicios en el mercado interior. Marcial Pons, Madrid.

De la Quadra-Salcedo Janini, T. (2007): “¿Quo Vadis Bolkenstein? ¿Armonización o mera desregulación de la prestación de servicios", Revista Española de Derecho Europeo, n. 22.

Fernández Farreres, G. (1998): "La infraestructura organizativa para la calidad y la seguridad industrial y el fenómeno del ejercicio por particulares de funciones públicas de inspección y control" en Revista Aragonesa de Administración Pública, n. ${ }^{\circ} 13$.

Fernández Rodríguez, T.R. (2007): “Un nuevo Derecho Administrativo para el mercado interior europeo", Revista Española de Derecho Europeo, n. 22.

González García, J.V. (2009): "La transposición de la Directiva de servicios: aspectos normativos y organizativos en el Derecho español" Revista Española de Derecho Europeo, n. 32 .

Gutiérrez Colomina, V. "La incidencia de la Directiva de servicios 2006/123/CE en el Urbanismo" documento disponible en http://www.inap.map.es/NR/rdonlyres/ BDF38206-06E4-435B-9E08-541A3B9C5DBD/o/8.pdf. (Acceso 29 de abril de 2010).

Linde Paniagua, E. (2008): “Notas sobre el objeto, ámbito y reglas de aplicación de la Directiva relativa a los servicios en el mercado interior" Revista de Derecho de la Unión Europea, n. ${ }^{\circ} 14$.

Macera, B.F. (2000): “La problemática de la asunción de la inspección administrativa por entidades privadas. Especial referencia al sistema de vigilancia ambiental de las actividades clasificadas" en El Derecho Administrativo en el umbral del siglo XXI. Homenaje al profesor Dr. Ramón Martín Mateo. Tirant Lo Blanch, Valencia.

Martínez García, V. (2009): “La seguridad industrial y la Ley Ómnibus” Técnica Industrialn. ${ }^{\circ} 283$, septiembre-octubre.

Muñoz Machado, S. (2009): "Ilusiones y conflictos derivados de la Directiva de Servicios" Revista General de Derecho Administrativo, n. 21.

Nevado-Batalla Moreno, P.T. (2000): La intervención administrativa en la industria: seguridad y control. Comares, Granada.

Nogueira López, A. (2009): "Entidades colaboradoras con la Administración, libre prestación de servicios y régimen de control preventivo de las actividades" $R e$ vista Aranzadi de Derecho Ambiental, n. 16.

Ocharán de la Cámara, E. (1981): "Las entidades colaboradoras de la Administración 226 en la CEE”, Economía Industrial, vol. 207, n. ${ }^{\circ} 3$. 
Ojeda Marín, A. (1982): “Entidades privadas colaboradoras de la Administración en el ámbito técnico", en Homenaje a José Antonio García-Trevijano Fos. Colegio Universitario de Estudios Financieros-Instituto de Estudios de la Administración Local, Madrid.

Padrós Reig, C. (2000): Actividad administrativa y entidades colaboradoras. Tecnos, Madrid.

Padrós Reig, C. (2007): La competència autonòmica executiva sobre el règim administratiu de les activitats d'inspecció tècnica. Institut d'Estudis Autonòmics. Generalitat de Catalunya.

Padrós Reig, C. (2010): La Administración invisible. Panorama general y ejemplos prácticos de entidades colaboradoras de la Administración pública. Dykinson, Madrid.

Parejo Alfonso, L. (2009a): “La desregulación de los servicios con motivo de la Directiva Bolkenstein. La interiorización con paraguas y en ómnibus de su impacto en nuestro sistema", El Cronista del Estado Social y Democrático de Derecho, n. 6.

Parejo Alfonso, L. (2009b): “La Directiva Bolkenstein y la Ley paraguas: ¿Legitima el fin cualesquiera medios para la reconversión del Estado "autoritativo"? Revista Española de Derecho Europeo, n. 32.

París I Domènech, N. y Corretja Torrens, M. (2010): “Aproximació al procés de transposició de la Directiva de Serveis: incidència en el sistema de distribució de competències dissenyat per la CE i l'EAC", Revista d'Estudis Autonómics i Federals, n. ${ }^{\circ} 10$.

Rivero Ortega, R. (2000): El estado vigilante. Consideraciones jurídicas sobre la función inspectora de la Administración. Tecnos, Madrid.

Rivero Ortega, R. (2009): "Antecedentes, principios generales y repercusiones administrativas de la Directiva de Servicios: problemas de su transposición en España", Revista de Estudios Locales, n. ${ }^{\circ} 122$.

Ruiz Ruiz, F. (1995): "Las competencias de las CCAA en el desarrollo normativo y la ejecución del derecho comunitario europeo" Revista Española de Derecho Constitucional, n. ${ }^{\circ} 45$.

Sainz-Moreno, F. (1983)"Ejercicio privado de funciones públicas" Revista de Administración pública, n. ${ }^{\circ} 100-102$.

Cassese, S. "La partecipazione dei privati alle decisioni pubbliche - Saggio di Diritto comparato" disponible en http://www.irpa.eu/public/File/Seminari\%2oDAC/Lezione\%20introduttiva\%20prof.\%20Sabino\%20Cassese.pdf

Recibido: 4 de junio de 2010

Aceptado: 7 de octubre de 2010 
